\title{
Scale-Up of Advanced Hot-Gas Desulfurization Sorbents
}

FINAL REPORT

K. Jothimurugesan

Hampton University

S. K. Gangwal

Research Triangle Institute

March 1998

Work Performed Under

Grant No: DE-FG22-95MT95011--05

For

U.S. Department of Energy

Office of Fossil Energy

Federal Energy Technology Center

Pittsburgh, PA 15236-0940 


\title{
Scale-Up of Advanced Hot-Gas Desulfurization Sorbents
}

\author{
FINAL REPORT
}

Work Performed Under

Grant No: DE-FG22-95MT95011

by

K. Jothimurugesan

Department of Chemical Engineering

School of Engineering \& Technology

Hampton University

Hampton, Virginia 23668

Santosh K. Gangwal

Research Triangle Institute

P.O. Box 12194

Research Triangle Park, NC 27709

For

U.S. Department of Energy

Office of Fossil Energy

Federal Energy Technology Center

Pittsburgh, PA 15236-0940 


\section{DISCLAIMER}

This report was prepared as an account of work sponsored by an agency of the United States Government. Neither the United States Government nor any agency thereof, nor any of their employees, makes any warranty, express or implied, or assumes any legal liability or responsibility for the accuracy, completeness, or usefulness of any information, apparatus, product, or process disclosed, or represents that its use would not infringe privately owned rights. Reference herein to any specific commercial product, process, or service by trade name, trademark, manufacturer, or otherwise, does not necessarily constitute or imply its endorsement, recommendation, or favoring by the United States Government or any agency thereof. The views and opinions of authors expressed herein do not necessarily state or reflect those of the United States Government or any agency thereof. 


\section{EXECUTIVE SUMMARY}

This report describes the project, "Scale-Up of Advanced Hot-Gas Desulfurization Sorbents" sponsored by U.S. Department of Energy, Federal Energy Technology Center under Grant No. DE-FG-22-95MT95011. The work was performed by Hampton University (prime contractor) with support by Research Triangle Institute (RTI) as subcontractor. United Catalysts, Inc. (UCI) provided advice and assistance in sorbent preparation and scale up.

Hot-Gas Desulfurization (HGD) of fuel gas in integrated gasification combined cycle (IGCC) power systems has received a great deal of attention over the past two decades due to the potential for high thermal efficiency (up to $47 \%$ ) and low environmental impact of these advanced power systems using HGD. In an IGCC system coal is gasified at elevated pressures, typically 20 to 30 atm, to produce a low-volume fuel gas which is desulfurized prior to burning in a combustion turbine to produce electricity. Higher efficiency and lower cost are achieved by efficient integration of modular designs of the gasification, hot-gas cleanup, and turbine subsystems. Gas cleaning primarily involves removal of particulates and sulfur compounds -mostly $\mathrm{H}_{2} \mathrm{~S}$ and some carbonyl sulfide (COS). Sorbents based on zinc oxide, currently the leading candidates, can effectively reduce the $\mathrm{H}_{2} \mathrm{~S}$ in coal gas to around $10 \mathrm{ppm}$ levels and can be regenerated for multicycle operation. However, all current first-generation leading sorbents undergo significant loss of sulfidation reactivity and capacity with cycling, as much as $50 \%$ or greater loss in only $25-50$ cycles. Stability of the hot-gas desulfurization sorbents over at least one hundred cycles is essential for improved IGCC economics over conventional power plants. 
The objective of this study was to develop advanced regenerable sorbents for hot gas desulfurization in IGCC systems. The specific objective was to develop durable advanced sorbents that demonstrate a strong resistance to attrition and chemical deactivation, and high sulfidation activity at temperatures as low as $343^{\circ} \mathrm{C}\left(650^{\circ} \mathrm{F}\right)$.

Twenty sorbents were synthesized in this work. Details of the preparation technique and the formulations are proprietary, pending a patent application, thus no details regarding the technique are divulged in this report. Sulfidations were conducted with a simulated gas containing (vol \%) $10 \mathrm{H}_{2}, 15 \mathrm{CO}, 5 \mathrm{CO}_{2}, 0.4-1 \mathrm{H}_{2} \mathrm{~S}, 15 \mathrm{H}_{2} \mathrm{O}$, and balance $\mathrm{N}_{2}$ in the temperature range of $343-538^{\circ} \mathrm{C}$. Regenerations were conducted at temperatures in the range of $400-600^{\circ} \mathrm{C}$ with air- $\mathrm{N}_{2}$ mixtures. To prevent sulfation, catalyst additives were investigated that promote regeneration at lower temperatures. Characterization were performed for fresh, sulfided and regenerated sorbents.

Based on fixed-bed microreactor screening of numerous sorbent powders, an attritionresistant fludizable sorbent designated MCRH-61 was selected for high temperature, high pressure (HTHP) testing. A 10 cycle test was conducted using HTHP 2.0-inch fludized-bed reactor system. The sorbent demonstrated high reactivity over the 10 cycle test and its attrition resistance was comparable to equilibrium fluidized cracking catalyst (FCC). However, sulfate formation was observed during neat air regeneration at elevated pressures. These promising test results indicated that an optimized MCRH-61 could be a good candidate sorbent for the SierraPacific clean coal project or similar project involving transport reactor. UCI scaled up a modified version of the MCRH-61 sorbent to $100 \mathrm{lb}$ to demonstrate commercial readiness.

A number of publications and presentations have resulted from this project. These are 
listed below:

\section{PUBLICATION/PRESENTATION}

1. K. Jothimurugesan, A.A. Adeyiga and S.K. Gangwal "Regenerable Sorbents for Desulfurization of Coal Gas", Fourth Annual HBCUs/Private Sector Energy Research and Development Technology Transfer symposium, Greensboro, NC, April 2-4, 1996.

2. K. Jothimurugesan "Performance of Zinc Based Sulfur Sorbents on Coal Derived Fuel Gas", Fifth Annual Historically Black Colleges and Universities and Other Minority Institutions Program-Energy Research and Development Technology Transfer Symposium, Baton Rouge, LA. March 4-6, 1997

3. S.K. Gangwal and K. Jothimurugesan "Attrition-Resistant catalysts and Sorbents for Fluidized-Bed and Slurry Bubble Column Processes”. U.S. Patent Pending, 1997.

4. K. Jothimurugesan, S.K. Gangwal, R. Gupta, and B.S. Turk "Advanced Hot-gas Desulfurization Sorbents" Advanced Coal-Based Power and Environmental Systems'97 Conference, Federal Energy Technology Center, Pittsburgh, Pennsylvania, July 22-24, 1997.

5. K. Jothimurugesan, S.K. Gangwal, R. Gupta, and B.S. Turk "Advanced Hot-gas Desulfurization Sorbents" Proceedings of the Advanced Coal-Based Power and Environmental Systems'97 Conference, Federal Energy Technology Center, Pittsburgh, Pennsylvania, November, 1997. 


\section{ACKNOWLEDGMENTS}

This study was sponsored by the U.S. Department of Energy (DOE) under Grant No: DE-FG-2295MT95011. The authors would like to acknowledge with gratitude the guidance provided by the DOE Contracting Officers's Representative, Dr. Kamalendu Das, of the Federal Energy Technology Center. United Catalysts, Inc. assisted with preparations of sorbents. The hightemperature, high pressure fluidized-bed testing was conducted at RTI using their 2.0 inch reactor system. These tests were conducted by Dr. R. Gupta and Dr. B. Turk of RTI under contract No: DE-AC21-88MC25006. 


\section{CONTENTS}

Section

$\underline{\text { Page }}$

Executive Summary $\ldots \ldots \ldots \ldots \ldots \ldots \ldots \ldots \ldots \ldots \ldots \ldots \ldots \ldots \ldots$ iii

Acknowledgment ......................... vi

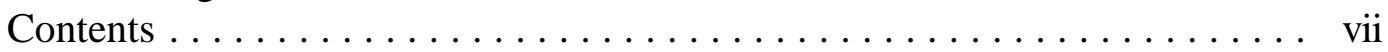

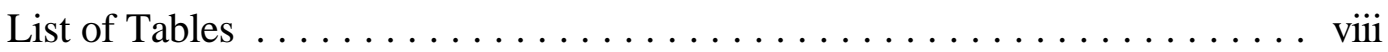

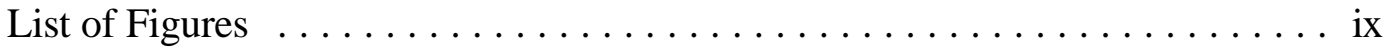

$1.0 \quad$ Introduction. $\ldots \ldots \ldots \ldots \ldots \ldots \ldots \ldots \ldots \ldots \ldots \ldots \ldots \ldots$

$1.1 \quad$ Project Objectives. $\ldots \ldots \ldots \ldots \ldots \ldots \ldots \ldots \ldots \ldots \ldots \ldots \ldots \ldots \ldots$

Description of Project Tasks $\ldots \ldots \ldots \ldots \ldots \ldots \ldots \ldots \ldots \ldots \ldots \ldots \ldots \ldots \ldots \ldots \ldots$

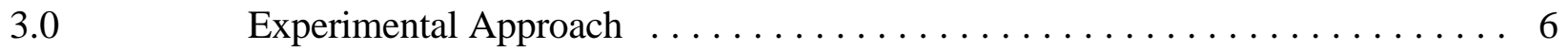

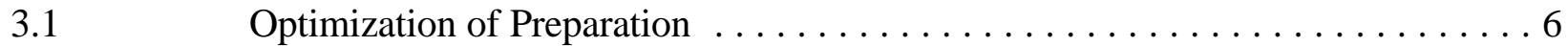

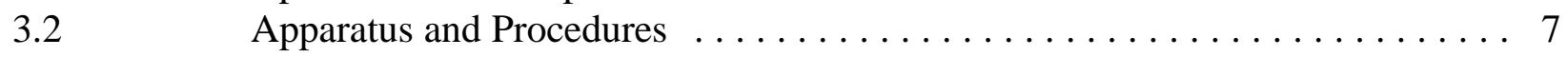

Results and Discussions $\ldots \ldots \ldots \ldots \ldots \ldots \ldots \ldots \ldots \ldots \ldots \ldots \ldots \ldots \ldots \ldots \ldots$

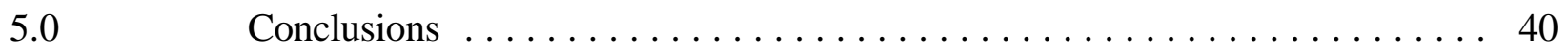

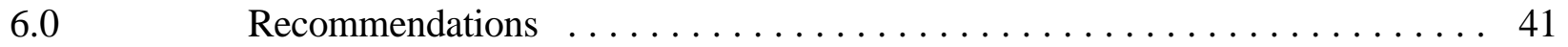

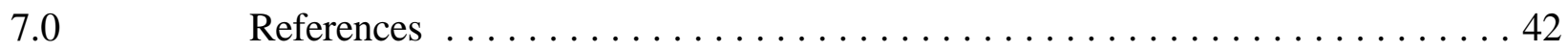




\section{LIST OF TABLES}

Number $\quad \underline{\text { Page }}$

1 Properties of Fresh MCRH Sorbents $\ldots \ldots \ldots \ldots \ldots \ldots \ldots \ldots \ldots \ldots \ldots \ldots$

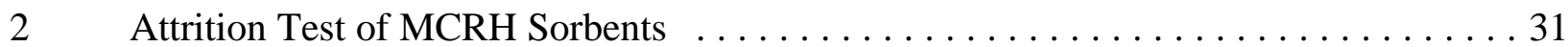

3 Sorbent Selection Criteria for Sierra-Pacific. $\ldots \ldots \ldots \ldots \ldots \ldots \ldots \ldots \ldots \ldots$ 
Number

\section{LIST OF FIGURES}

1. HGD Laboratory - Scale Fixed-Bed Reactor System $\ldots \ldots \ldots \ldots \ldots \ldots \ldots \ldots \ldots \ldots$

2. SEM Micrographs of MCRH-41 Fresh Sorbents. $\ldots \ldots \ldots \ldots \ldots \ldots \ldots \ldots \ldots \ldots \ldots$

3. SEM Micrographs of MCRH-42 Fresh Sorbents. $\ldots \ldots \ldots \ldots \ldots \ldots \ldots \ldots \ldots \ldots \ldots$

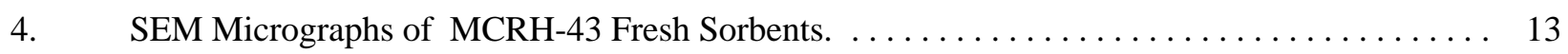

5. SEM Micrographs of MCRH-44 Fresh Sorbents. $\ldots \ldots \ldots \ldots \ldots \ldots \ldots \ldots \ldots \ldots \ldots$

6. SEM Micrographs of MCRH-45 Fresh Sorbents. $\ldots \ldots \ldots \ldots \ldots \ldots \ldots \ldots \ldots \ldots \ldots$

7. $\mathrm{H}_{2} \mathrm{~S}$ Breakthrough Curves in Successive Sulfidation Cycles of MCRH-41 Sorbent $\ldots \ldots \ldots 16$

8. $\quad \mathrm{H}_{2} \mathrm{~S}$ Breakthrough Curves in Successive Sulfidation Cycles of MCRH-42 Sorbent $\ldots \ldots \ldots 17$

9. $\quad \mathrm{H}_{2} \mathrm{~S}$ Breakthrough Curves in Successive Sulfidation Cycles of MCRH-43 Sorbent $\ldots \ldots \ldots 18$

10. $\mathrm{H}_{2} \mathrm{~S}$ Breakthrough Curves in Successive Sulfidation Cycles of M CRH-44 Sorbent . . . . . . 19

11. $\mathrm{H}_{2} \mathrm{~S}$ Breakthrough Curves in Successive Sulfidation Cycles of M CRH-45 Sorbent . . . . . . 20

12. SEM Micrographs of MCRH-46 Fresh Sorbents. $\ldots \ldots \ldots \ldots \ldots \ldots \ldots \ldots \ldots \ldots \ldots \ldots \ldots$

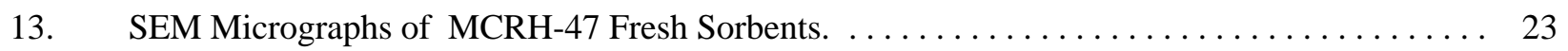

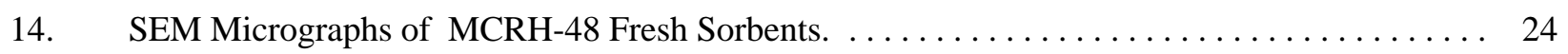

15. $\mathrm{H}_{2} \mathrm{~S}$ Breakthrough Curves in Successive Sulfidation Cycles of M CRH-46 Sorbent . . . . . . 25

16. $\mathrm{H}_{2} \mathrm{~S}$ Breakthrough Curves in Successive Sulfidation Cycles of M CRH-47 Sorbent . . . . . . 26

17. $\mathrm{H}_{2} \mathrm{~S}$ Breakthrough Curves in Successive Sulfidation Cycles of M CRH-48 Sorbent . . . . . . 27

18. $\mathrm{H}_{2} \mathrm{~S}$ Breakthrough Curves in Successive Sulfidation Cycles of M CRH-50 Sorbent . . . . . 28

19. $\mathrm{H}_{2} \mathrm{~S}$ Breakthrough Curves in Successive Sulfidation Cycles of M CRH-61 Sorbent $\ldots \ldots \ldots 33$

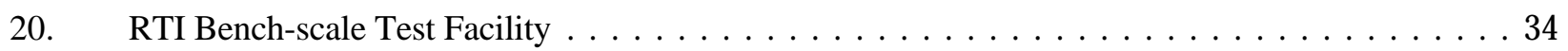

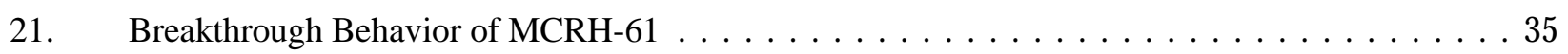

22. $\mathrm{SO}_{2}$ Evolution During Sulfidation due to Sulfation $\ldots \ldots \ldots \ldots \ldots \ldots \ldots \ldots \ldots \ldots \ldots \ldots$ 
23. Cumulative Sulfur $\mathrm{L}$ oading for $\mathrm{MCRH}-61 \ldots \ldots \ldots \ldots \ldots \ldots$

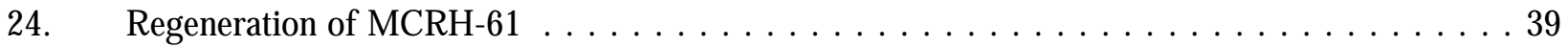




\subsection{INTRODUCTION}

Advanced integrated gasification combined cycle (IGCC) power plants are being developed to produce electricity from coal due to their potential for superior environmental performance, economics, and efficiency in comparison to conventional coal-based power plants. The U.S. Department of Energy (DOE), Federal Energy Technology Center (FETC) Clean Coal Technology program has led to the successful construction of two such advanced plants--Sierra Pacific and Tampa Electric Company (TECO), with shakedown and commissioning currently in progress. A key component of these advanced IGCC plants is a hot-gas desulfurization (HGD) process that employs efficient regenerable zinc-based mixed-metal oxide sorbents. These sorbents can remove the hydrogen sulfide $\left(\mathrm{H}_{2} \mathrm{~S}\right)$ in coal gas to $<20 \mathrm{ppmv}$ and that can be regenerated with air for multi-cycle operation.

The chemistry of a complete sulfidation-regeneration cycle may be represented by the overall reactions:

\section{Reduction}

$$
\begin{aligned}
& \mathrm{H}_{2,} \mathrm{CO} \\
& \mathrm{MO}_{\mathrm{x}} \quad-\cdots \rightarrow \mathrm{MO}_{\mathrm{y}} \quad(\mathrm{y} \leq \mathrm{x}) \\
& \text { Sulfidation } \\
& \mathrm{MO}_{\mathrm{y}}+\mathrm{yH}_{2} \mathrm{~S}=\mathrm{MS}_{\mathrm{y}}+\mathrm{yH}_{2} \mathrm{O} \\
& \mathrm{MS}_{\mathrm{y}} \mathrm{O}_{2}-\cdots \mathrm{M}\left(\mathrm{SO}_{4}\right)_{\mathrm{x}}+\mathrm{xSO}_{2} \cdots \mathrm{MO}_{\mathrm{x}}+\mathrm{xSO}_{2}
\end{aligned}
$$$$
\text { Regeneration }
$$

where $M$ is a metal $\mathrm{Fe}, \mathrm{Zn}$, etc.

A number of metal oxides have been and/or are currently being evaluated as regenerable sorbents (Gangwal et al., 1995). These include oxides of copper, cerium, manganese, cobalt, tin, iron, and zinc, both individually and in combinations. The chemistry associated with the use of 
these sorbents is generally similar with a few exceptions. These metal oxide or mixed-metal oxide sorbents have been investigated with and without a secondary oxide such as silica, alumina, titania, and chromia. These secondary oxide act as supports for strengthening mechanical structure, stabilizers against reduction of the metal oxide to metal in a reducing environment, and modifiers of thermodynamic properties of the metallic oxide (by forming a perovskite type structure) to enhance elemental sulfur formation during regeneration.

The bulk of research on regenerable sorbents has been on zinc-based sorbents because sorbents based on zinc oxide appear to have the fewest technical problems among all sorbents. Zinc oxide has highly attractive thermodynamics for $\mathrm{H}_{2} \mathrm{~S}$ adsorption and can reduce the $\mathrm{H}_{2} \mathrm{~S}$ to parts-per-million levels over a very wide temperature range. Iron oxide appears to be the next most popular sorbent; however, the thermodynamics for iron is not very attractive. Also iron oxide can readily undergo reduction $\left(\mathrm{Fe}_{2} \mathrm{O}_{3} \rightarrow \mathrm{Fe}_{3} \mathrm{O}_{4} \rightarrow \mathrm{FeO} \rightarrow \mathrm{Fe}\right)$ depending on the reducing power of coal gas. This can consume valuable fuel gas and cause sorbent deterioration. Iron oxide can also catalyze carbon formation if sufficient steam is not present in the fuel gas.

A temperature range of 550 to $750^{\circ} \mathrm{C}$ received the major research emphasis in the United States during the 1980 s and early 1990s. Because of zinc oxide's potential for reduction ( $\mathrm{ZnO}+$ $\left.\mathrm{H}_{2} \rightarrow \mathrm{Zn}+\mathrm{H}_{2} \mathrm{O}\right)$ at $>600^{\circ} \mathrm{C}$ followed by evaporation, a zinc oxide-titanium oxide sorbent, namely zinc titanate sorbent, was developed and tested at high temperature and high pressure (Gangwal et al., 1988; Jothimurugesan and Harrison, 1990; Stephanpoulos and Jothimurugesan, 1990; Woods et al., 19990;1991). Zinc titanate is currently one of the leading sorbents. However, all current first-regeneration leading sorbents undergo significant loss of reactivity with cycling, as much as $50 \%$ or greater loss in only $25-50$ cycles. Stability of the hot-gas desulfurization sorbent 
over 100s of cycles is essential for improved IGCC economics over conventional power plants.

During recent years, research emphasis has shifted toward lower temperatures (350 to $550{ }^{\circ} \mathrm{C}$ ) based on a study in the Netherlands (NOVEM, 1991). According to this study, the thermal efficiency of a 800 MWe IGCC plant increased from $42.75 \%$ using cold-gas cleanup to $45.14 \%$ using $\mathrm{HGD}$ at $350^{\circ} \mathrm{C}$ and to $45.46 \%$ using $\mathrm{HGD}$ at $600^{\circ} \mathrm{C}$. The small efficiency increase from 350 to $600^{\circ} \mathrm{C}$ suggested that the temperature severity of the hot-gas cleanup devices can be somewhat reduced without significant loss of thermal efficiency. An important reason for development of sorbents in the temperature range suggested above is the reduction of the operating temperature of the upstream ceramic candle filter which have not provided reliable long-term operation at high temperatures. Reduction in the hot-gas cleanup temperature would also result in reduction in semi-volatile contaminants (e.g. alkali vapors), which may be particularly damaging to ceramic filters, through capture on to particles. Another important reason to reduce hot-gas cleanup severity is to reduce the operating temperatures and temperature swings of on-off valves and vessels for cyclic fixed-bed desulfurization/regeneration systems, lock-hopper valves for moving-bed applications, and the turbine load control valves.

Many of the sorbent materials limitations we face today exist because of our inability to successfully synthesize a specific compound with the desired properties. Metal oxides containing more than one type of cation are of interest from both a practical and fundamental point of view. Metal oxides have many applications in chemical and petrochemical processing as supports for catalytically active materials and as regenerable mixed oxide sorbents. Although the preparation of solid state materials has been practiced from earliest times, there remains a critical need to understand this process. Only through an understanding of materials preparation 
can we hope to develop creative approaches to synthesis.

Conventional mixed oxide preparation techniques used for the leading first generation sorbents do not usually produce molecularly homogeneous, high-surface-area materials. Bulk mixed oxide compounds are typically prepared by the solid compounding technique. This involves several cycles of powder mixing and firing at high temperatures (usually higher than $900-1000^{\circ} \mathrm{C}$ ) to affect the solid state reaction. The mixed oxide powder thus prepared is further processed conventionally by mixing with inorganic and organic additives and water followed by extrusion or pelletization, drying and heat treatment. These materials are often sintered, i.e., they consists of large grains with low surface area, and have relatively low pore volumes in order to preserve high mechanical strength. If a large amount of organic additive is used to create high porosity during the heating step, the pore volume of the material increases, albeit at the expense of the compressive crush strength. In the area of fuel gas cleanup at high temperatures, regenerable mixed oxide sorbents that combine relatively high surface area, high pore volume and good mechanical strength are needed to meet the requirements of cyclic high- temperature operation at high efficiency.

\section{$1.1 \quad$ PROJECT OBJECTIVES}

The objective of this project was to develop advanced regenerable sorbents for hot gas desulfurization in IGCC systems. The specific objective was to develop durable advanced sorbents that demonstrate a strong resistance to attrition and chemical deactivation, and high activity at temperatures as low as $343^{\circ} \mathrm{C}\left(650^{\circ} \mathrm{F}\right)$. 


\subsection{DESCRIPTION OF PROJECT TASKS}

TASK 1: Optimization of Preparation

The objectives of this task were to identify the parameters which play a role in the quality of the sorbent : starting raw material, concentrations and ageing etc. A detailed description of sorbent preparation is given in section 3.1 of the report. Section 3.1 also describes the various analytical techniques employed for sorbent characterization.

TASK 2: Investigation of Scale-Up

The objectives of this task were to scale up the equipment to make $500 \mathrm{~g}$ of material from $50 \mathrm{~g}$ and evaluate the performance of various sorbents under similar conditions in a fixed-bed microreactor. Section 3.2 describe the experimental apparatus and procedures employed throughout the project. Sorbent comparisons were carried out under the following operating conditions:

$\mathrm{P}=1 \mathrm{~atm}, \mathrm{~T}=343-538^{\circ} \mathrm{C}$, Space Velocity (S.V.) $=2500 \mathrm{~h}^{-1}$

Sulfidation Gas (vol \%): $10 \mathrm{H}_{2}, 15 \mathrm{CO}, 5 \mathrm{CO}_{2}, 0.4-1 \mathrm{H}_{2} \mathrm{~S}, 15 \mathrm{H}_{2} \mathrm{O}$, balance $\mathrm{N}_{2}$. Regeneration gas (vol \%): 10 air-90 $\mathrm{N}_{2}$ At least four to five cycles of sulfidation/regeneration were run with each sorbents until stabilized performance was attained. Following these tests, the most promising sorbent was further tested in the multicycles.

TASK 3: Preparation of $100 \mathrm{lb}$ Batch

Once a successful procedure was established it would be given to UCI to scaled up the 
preparation of $100 \mathrm{lb}$ batch.

\subsection{EXPERIMENTAL APPROACH}

\section{TASK 1: $\quad 3.1$ OPTIMIZATION OF PREPARATION}

The sorbent is a zinc oxide based material. Sorbents were prepared by precipitation of soluble salts of appropriate metals with aqueous ammonia solution. Ultrapure zinc nitrate, iron nitrate, cobalt nitrate hexahydrate, nickel nitrate hexahydrate, copper nitrate and ammonium molybdate hexahydrate (all the chemicals were obtained from Aldrich) were used as the metal salts. The precipitation was carried out by adding the raw salt solution and the ammonia solution simultaneously under vigorous mixing at room temperature. The product of the precipitation was washed, separated by filtration, dried at $150^{\circ} \mathrm{C}$ for $12 \mathrm{~h}$, and then calcined in an air stream in the range of $600-800^{\circ} \mathrm{C}$. The product thus obtained was crushed and sieved to $-32+60$ mesh A detailed physical and chemical characterization of the fresh, sulfided and regenerated sorbent materials was carried out using the following analytical techniques.

1. X-ray powder diffraction patterns were obtained using a Phillips PW 1800 X-ray unit using $\mathrm{CuK} \alpha$ radiation. Analyses were conducted using a continuous scan mode at a scan rates of $0.05^{\circ} 2 \theta$ per second.

2. The BET Surface area of the sorbents were determined by $\mathrm{N}_{2}$ physisorption using a Micromeritics Gemini 2360 system. The samples were degassed in a Micromeritics Flow Prep 060 at $120^{\circ} \mathrm{C}$ for $1 \mathrm{~h}$ prior to each measurement.

3. Mercury-porosimetry was used for pore volume, bulk density, average pore diameter and pore size distribution determination. 
4. Atomic Absorption (AA) Spectrometry was used elemental composition analysis.

5. The SEM (Scanning Electron Microscopy) micrograph was taken using a Cambridge Stereoscan 100.

\subsection{APPARATUS AND PROCEDURES}

The sorbent materials prepared were tested in a laboratory scale high-temperature and high-pressure (HTHP) fixed bed reactor which is shown in Figure 1. Briefly, the experimental setup consisted of a gas delivery system, a fixed bed reactor, and a gas analysis system. In the gas delivery system, a simulated fuel gas of any desired composition could be generated using the bottled gases, a set of mass flow controllers, and high-pressure syringe pumps. Steam was added to the mixed dry gas by vaporizing liquid water injected into the gas stream at a controlled rate by a high pressure syringe pump. The reactor was made from a 3/4-inch stainless steel tube. Inside the 3/4-inch there was a removable 316 stainless steel $1.0 \mathrm{~cm}$ I.D pipe with a porous alumina plate in the bottom that acted as a gas distributor. The insert was Alon-processed to prevent corrosion of stainless steel by sulfurous gases in the presence of steam. The pressure in the reactor was controlled by a back pressure regulator and measured by an electronic pressure sensor. Thermocouples were positioned to measure the temperatures of the preheated feed gas, the reactor bed, and the product gas. The tests were conducted with a simulated gas nominally containing (vol \%) $10 \mathrm{H}_{2}, 15 \mathrm{CO}, 5 \mathrm{CO}_{2}, 1 \mathrm{H}_{2} \mathrm{~S}, 15 \mathrm{H}_{2} \mathrm{O}$, and balance $\mathrm{N}_{2}$. The outlet $\mathrm{H}_{2} \mathrm{~S}$ and $\mathrm{SO}_{2}$ concentrations were monitored using a gas chromatograph.

A typical run consists of loading the sorbent having a particle size range of $-32+64$ mesh and heating the reactor to a desired temperature of $350-500^{\circ} \mathrm{C}$ with continuous flow of nitrogen. Once the desired temperature was attained, the flow of fuel gas to the reactor was started and the 


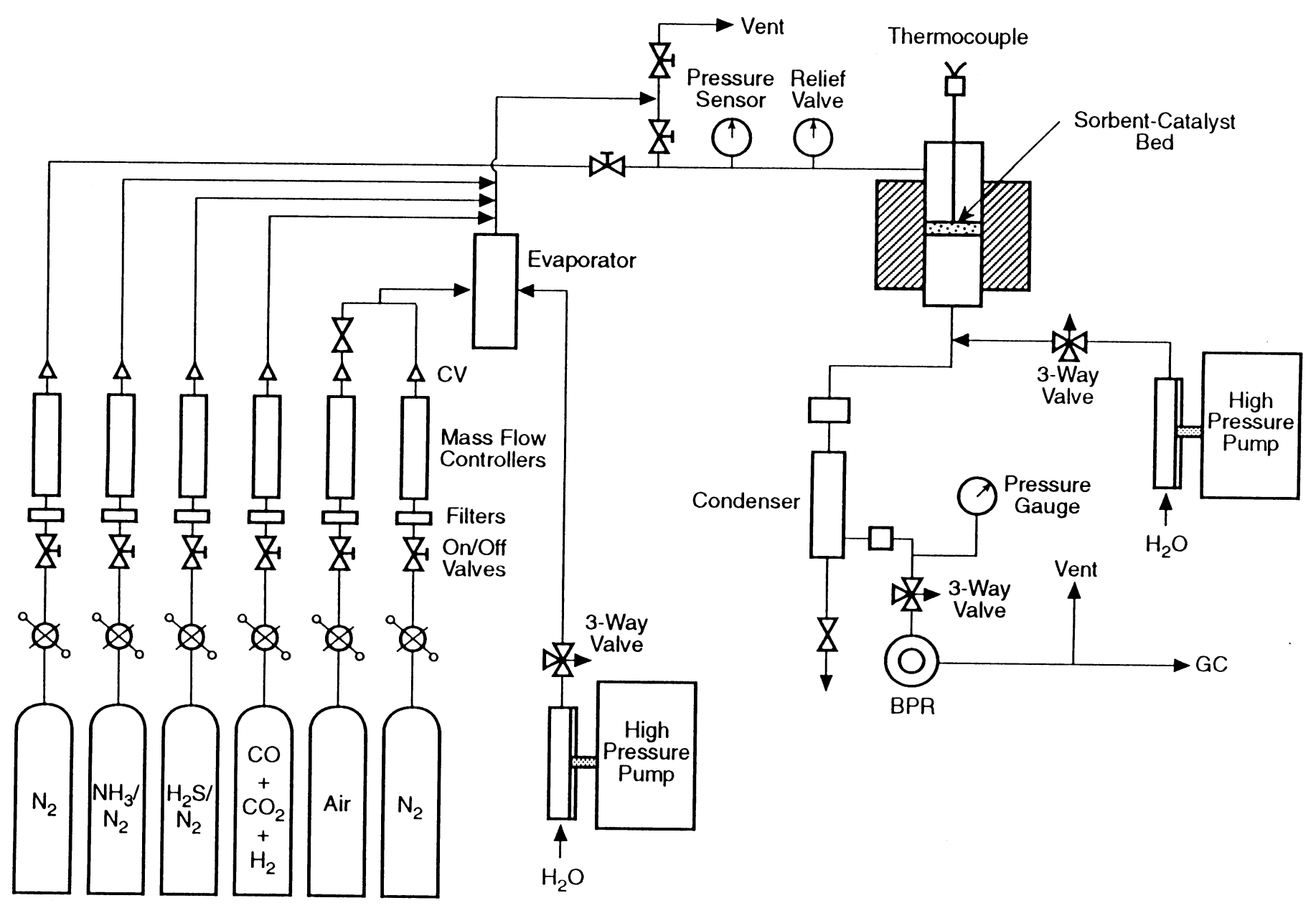

Figure 1. HGD Laboratory-Scale Fixed-Bed Reactor System 
concentration of $\mathrm{H}_{2} \mathrm{~S}$ was measured continuously in the effluent gas. When the $\mathrm{H}_{2} \mathrm{~S}$ concentration reaches $500 \mathrm{ppmv}$, the run was stopped and the system was prepared for regeneration. The regeneration of sulfided material was carried out at the desired temperature ranging between $400-550^{\circ} \mathrm{C}$ with 2 to 4 volume $\%$ oxygen in nitrogen. In all the runs, space velocity used was in the range of 2000-3000 $\mathrm{h}^{-1}$. The regeneration of the sulfided material was carried out until the $\mathrm{SO}_{2}$ concentration in the reactor effluent dropped below $50 \mathrm{ppm}$. These sulfidation-regeneration cycles were repeated as many times as desired. Typically each material was tested for 4 to 5 cycles to obtain meaningful data on material durability. At the end of a 4 to 5 cycle run, the material was removed from the reactor and all physical and chemical characterizations, as listed above, were carried out on the reacted material to determine changes due to reaction.

\subsection{RESULTS AND DISCUSSIONS}

From practical point of view, the main parameters which play a role in the quality of the precipitate are starting raw materials, concentrations, and ageing. The starting compounds was chosen on the basis of water solubility, commercial availability and low costs. These materials were chosen to avoid introducing deleterious elements in the final sorbent or that cause difficulties in subsequent processing. The concentrations of the salt solutions was optimized in the 0.05 Molar to 3.0 Molar range mainly to reduce the price of the final sorbent and favorable properties of the sorbent.

\section{Effect of Concentration}

The summary of the BET, pore volume results are presented in Table 1. As shown in 
Table 1, as the concentration of starting solutions is increased (at fixed ageing time) from 1.0 to 2.5 molar, the surface area of the sorbent decreases from 8.9 to $5.1 \mathrm{~m}^{2} / \mathrm{g}$. Also the pore volume decreases from 0.87 to 0.34 . The bulk density increases from 0.67 to $1.43 \mathrm{~g} / \mathrm{mL}$. The SEM morphology of the fresh MCRH 41, 42, 43, 44 and 45 are shown in Figures 2-6.

Table 1. Properties of fresh MCRH Sorbents

\begin{tabular}{|l|l|l|l|l|l|l|l|}
\hline Sorbent & $\begin{array}{l}\text { BET } \\
\text { Surface } \\
\text { Area, } \mathrm{m}^{2} / \mathrm{g}\end{array}$ & $\begin{array}{l}\text { Concent } \\
\text { ration }\end{array}$ & $\begin{array}{l}\text { Ageing, } \\
\text { min }\end{array}$ & $\begin{array}{l}\text { Pore } \\
\text { volume, } \\
\mathrm{mL} / \mathrm{g}\end{array}$ & $\begin{array}{l}\text { Avg Pore } \\
\text { Dia ( })\end{array}$ & $\begin{array}{l}\text { Bulk } \\
\text { Density, } \\
\mathrm{g} / \mathrm{mL}\end{array}$ & $\begin{array}{l}\text { Porosity, } \\
\%\end{array}$ \\
\hline MCRH-41 & 8.2 & $0.05 \mathrm{M}$ & 0 & 0.75 & 1904 & 0.7882 & 59.2 \\
\hline MCRH-42 & 8.9 & $1.0 \mathrm{M}$ & 0 & 0.87 & 2833 & 0.6753 & 58.9 \\
\hline MCRH-43 & 7.7 & $1.5 \mathrm{M}$ & 0 & 0.68 & 1398 & 0.7290 & 50.1 \\
\hline MCRH-44 & 6.0 & $2.0 \mathrm{M}$ & 0 & 0.52 & 1602 & 1.0149 & 52.9 \\
\hline MCRH-45 & 5.1 & $2.5 \mathrm{M}$ & 0 & 0.34 & 1320 & 1.4338 & 49.7 \\
\hline MCRH-46 & 7.3 & $1.0 \mathrm{M}$ & 30 & 0.82 & 2401 & 0.6967 & 57.5 \\
\hline MCRH-47 & 7.3 & $1.0 \mathrm{M}$ & 60 & 0.83 & 2368 & 0.6991 & 58.2 \\
\hline MCRH-48 & 6.4 & $1.0 \mathrm{M}$ & 90 & 0.84 & 2837 & 0.7098 & 59.6 \\
\hline MCRH-50 & NA & $1.0 \mathrm{M}$ & 180 & NA & NA & NA & NA \\
\hline
\end{tabular}

The ZnO-based sorbents MCRH-41, 42, 43, 44, 45 were evaluated in a sulfidation gas mixture containing (in vol $\%$ ): $\mathrm{H}_{2}=10 \%, \mathrm{CO}=15 \%, \mathrm{CO}_{2}=5 \%, \mathrm{H}_{2} \mathrm{~S}=1.0 \%, \mathrm{H}_{2} \mathrm{O}=15 \%$ and bal $\mathrm{N}_{2}$ and at a sulfidation temperature of $427^{\circ} \mathrm{C}$. Figures 7-11 show the $\mathrm{H}_{2} \mathrm{~S}$ breakthrough profiles as a function of time. Of the sorbents tested MCRH-42 (Fig 8.) showed excellent sulfidation behavior. The ratio $t / t^{*}$ gives an approximate value of the sorbent conversion, where $t$ is the actual run time, $\mathrm{t}^{*}$ is the theoretical time that would be required for complete conversion of the active sorbent oxides to metal sulfides. The pre-breakthrough $\mathrm{H}_{2} \mathrm{~S}$ level was less than $100 \mathrm{ppm}$ 


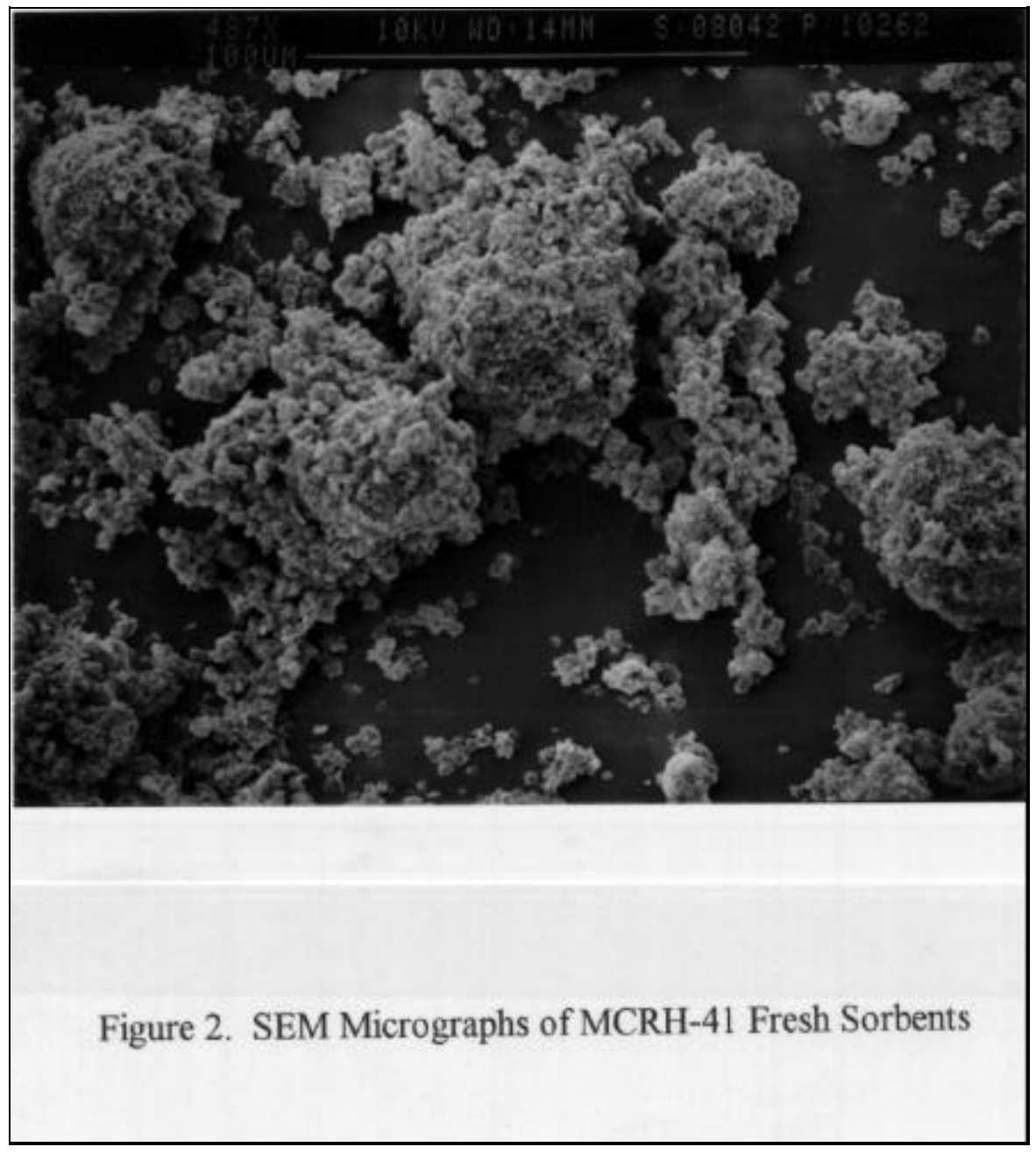




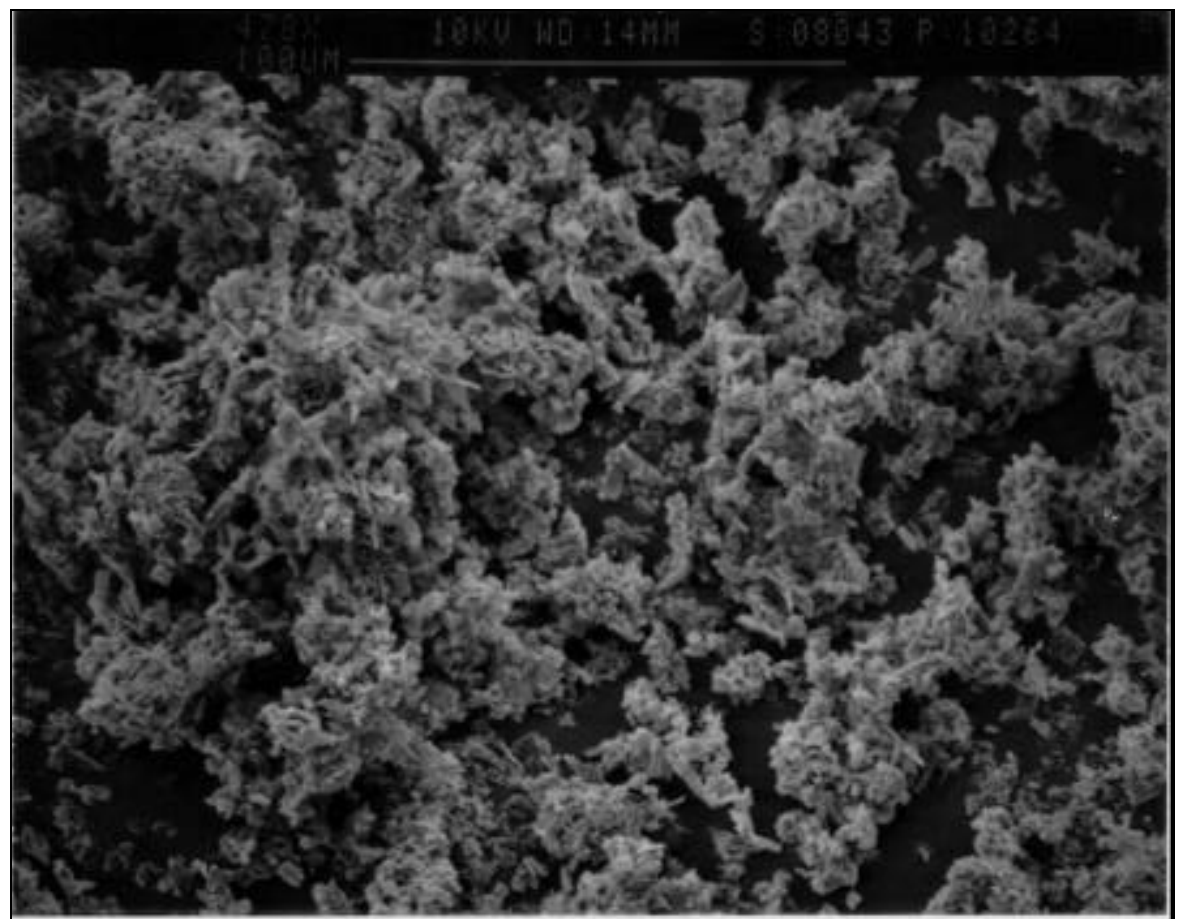

Figure 3. SEM Micrographs of MCRH-42 Fresh Sorbents 


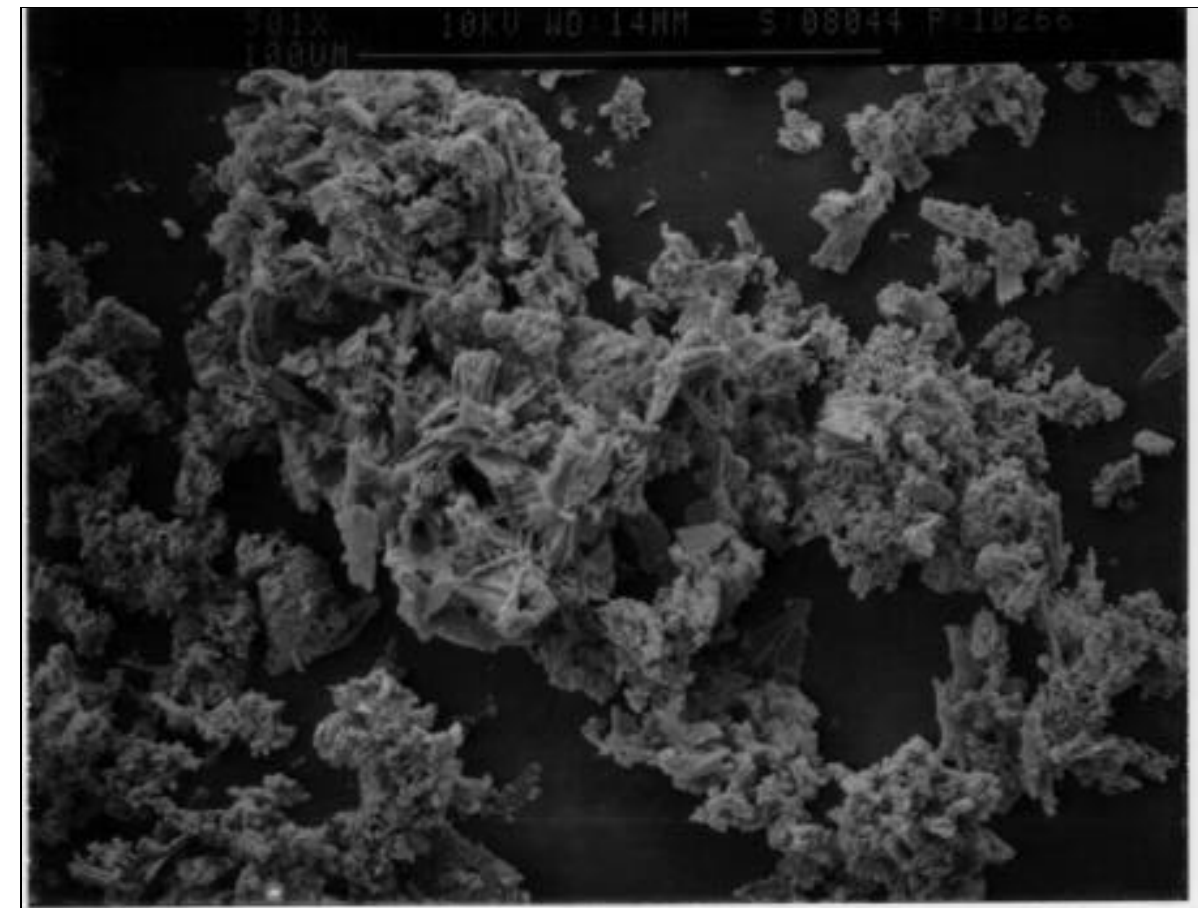

Figure 4. SEM Micrographs of MCRH-43 Fresh Sorbents 


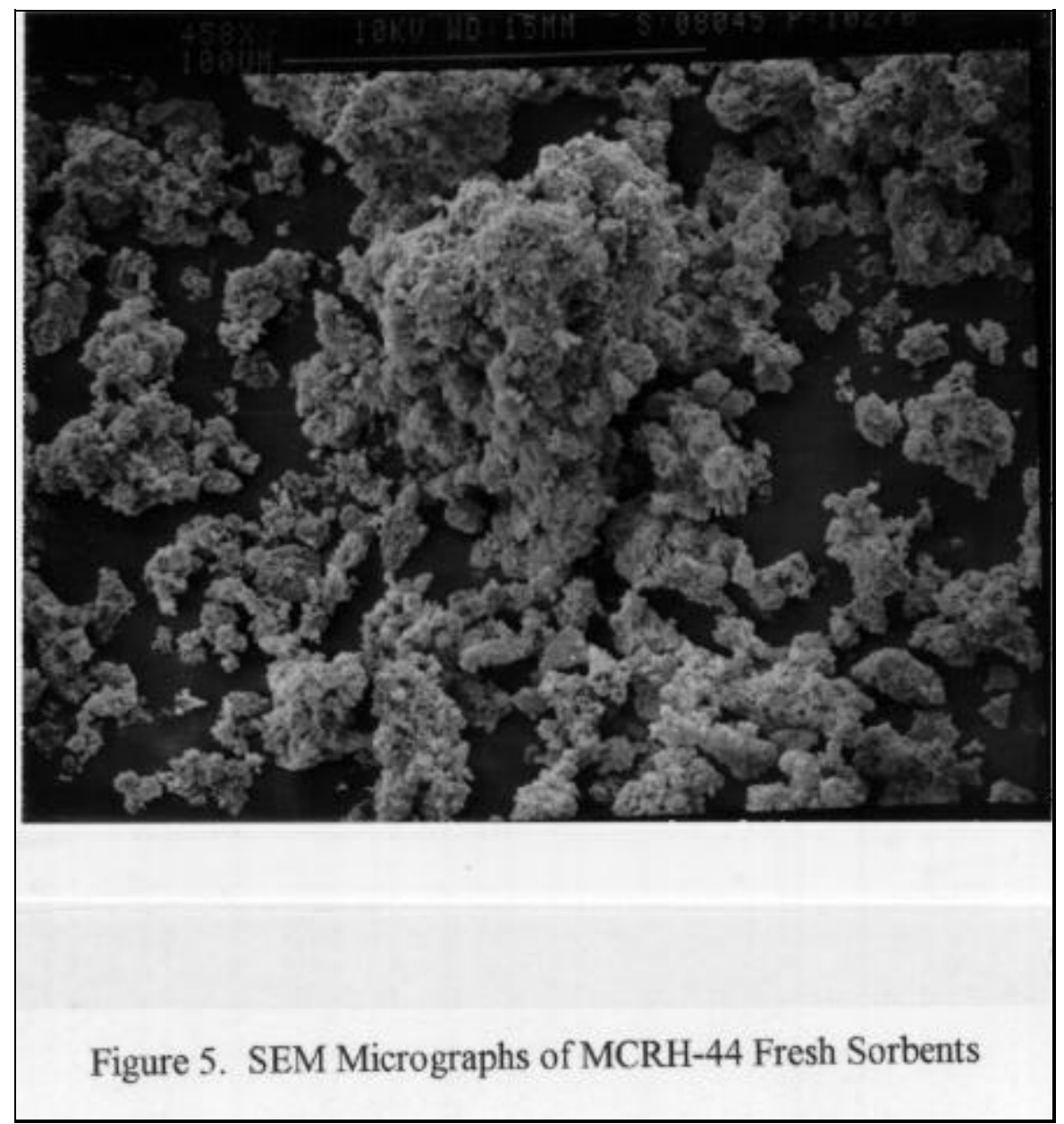




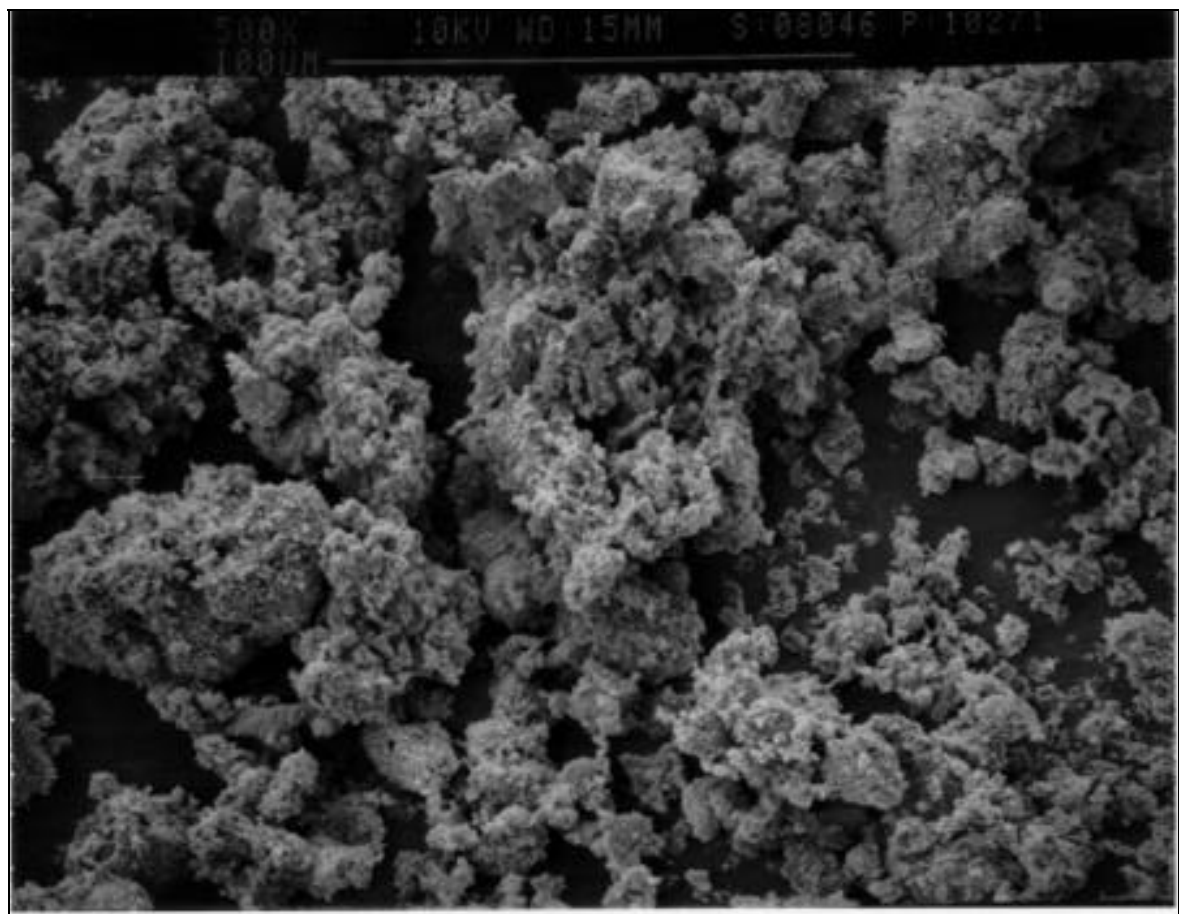

Figure 6. SEM Micrographs of MCRH-45 Fresh Sorbents 


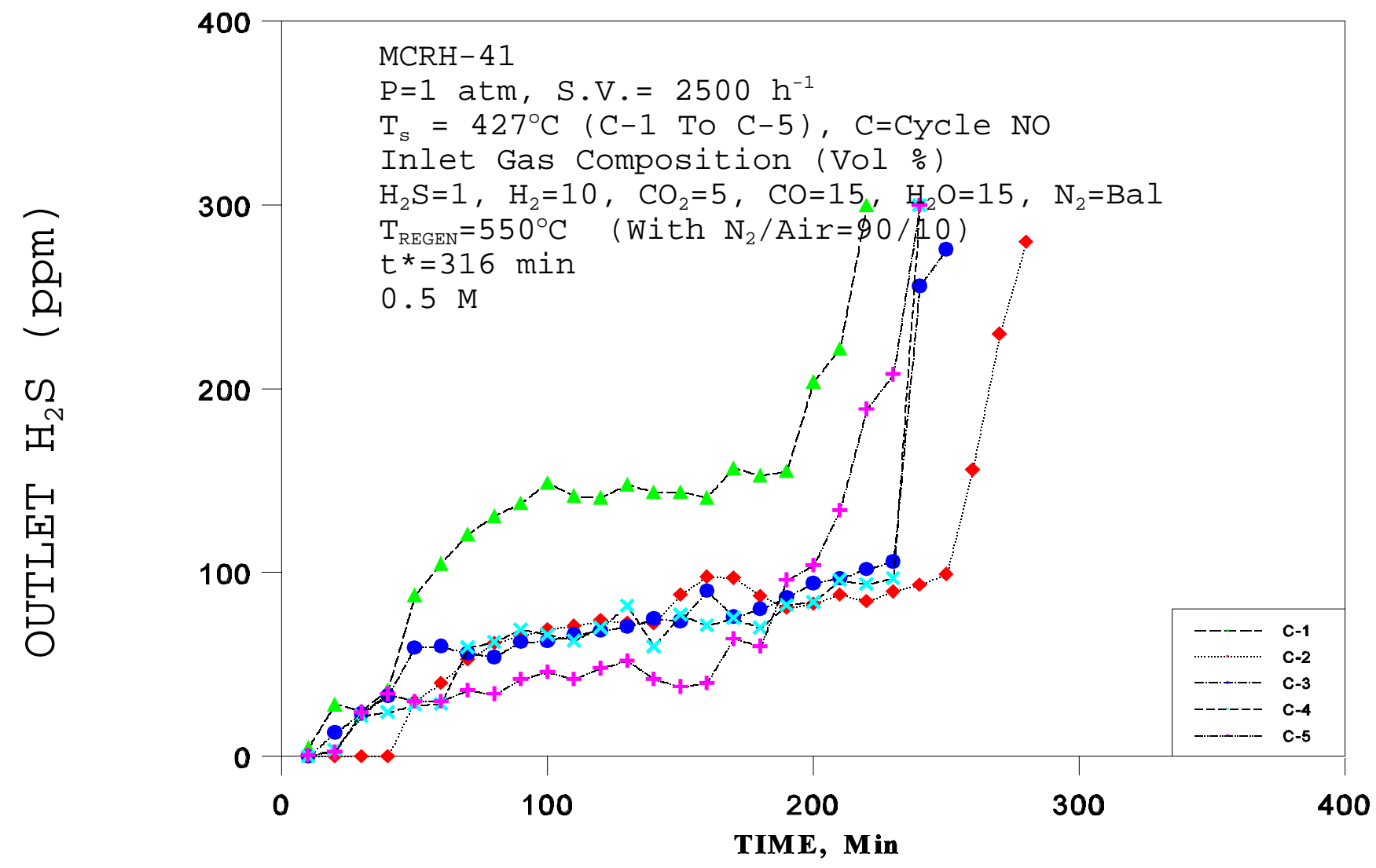

Figure 7. $\mathrm{H}_{2} \mathrm{~S}$ Breakthrough Curves in Successive Sulfidation Cycles of Sorbent MCRH-41 


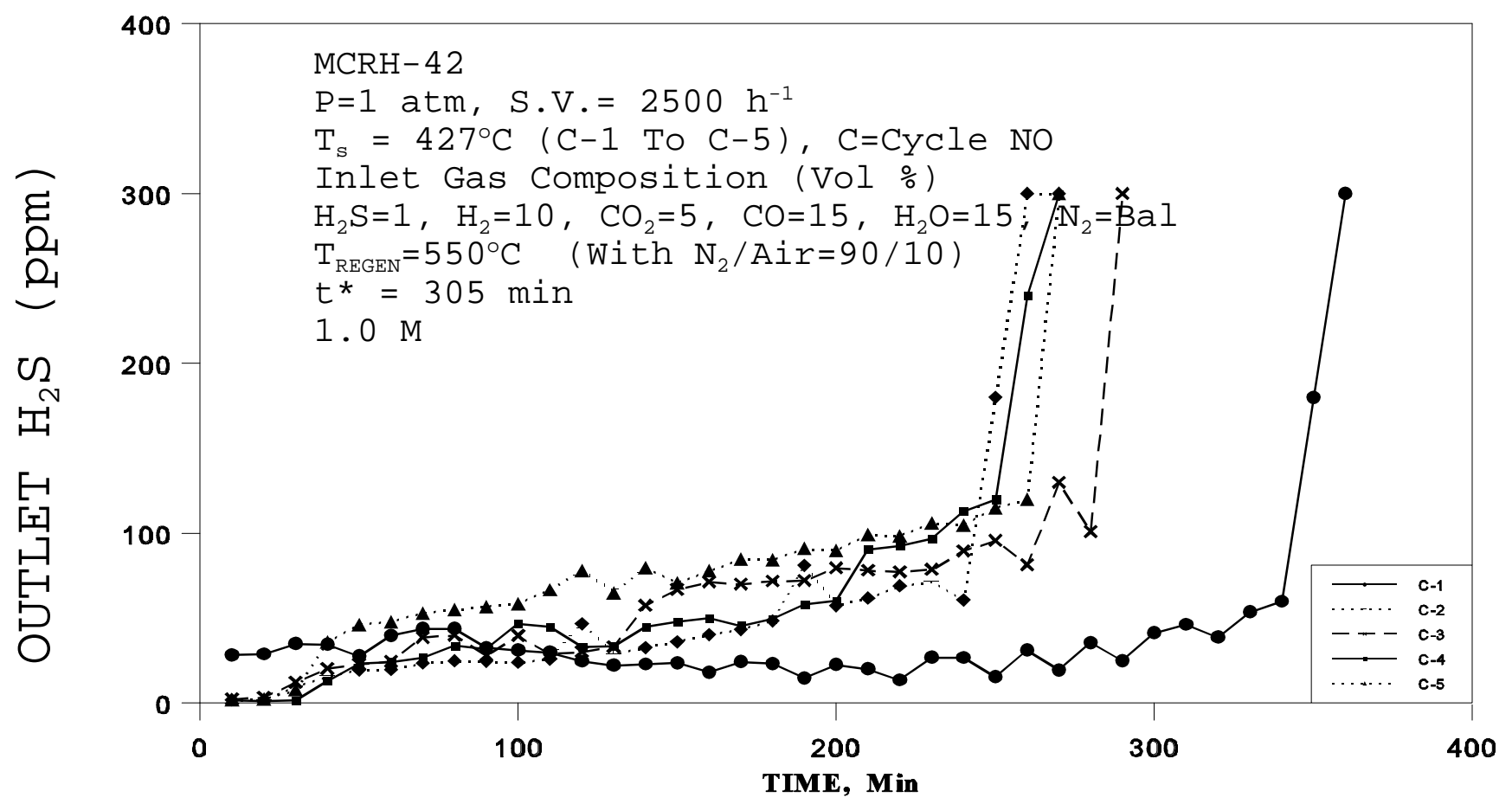

Figure 8. $\mathrm{H}_{2} \mathrm{~S}$ Breakthrough Curves in Successive Sulfidation Cycles of SorbentMCRH-42 


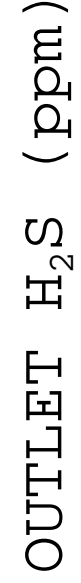

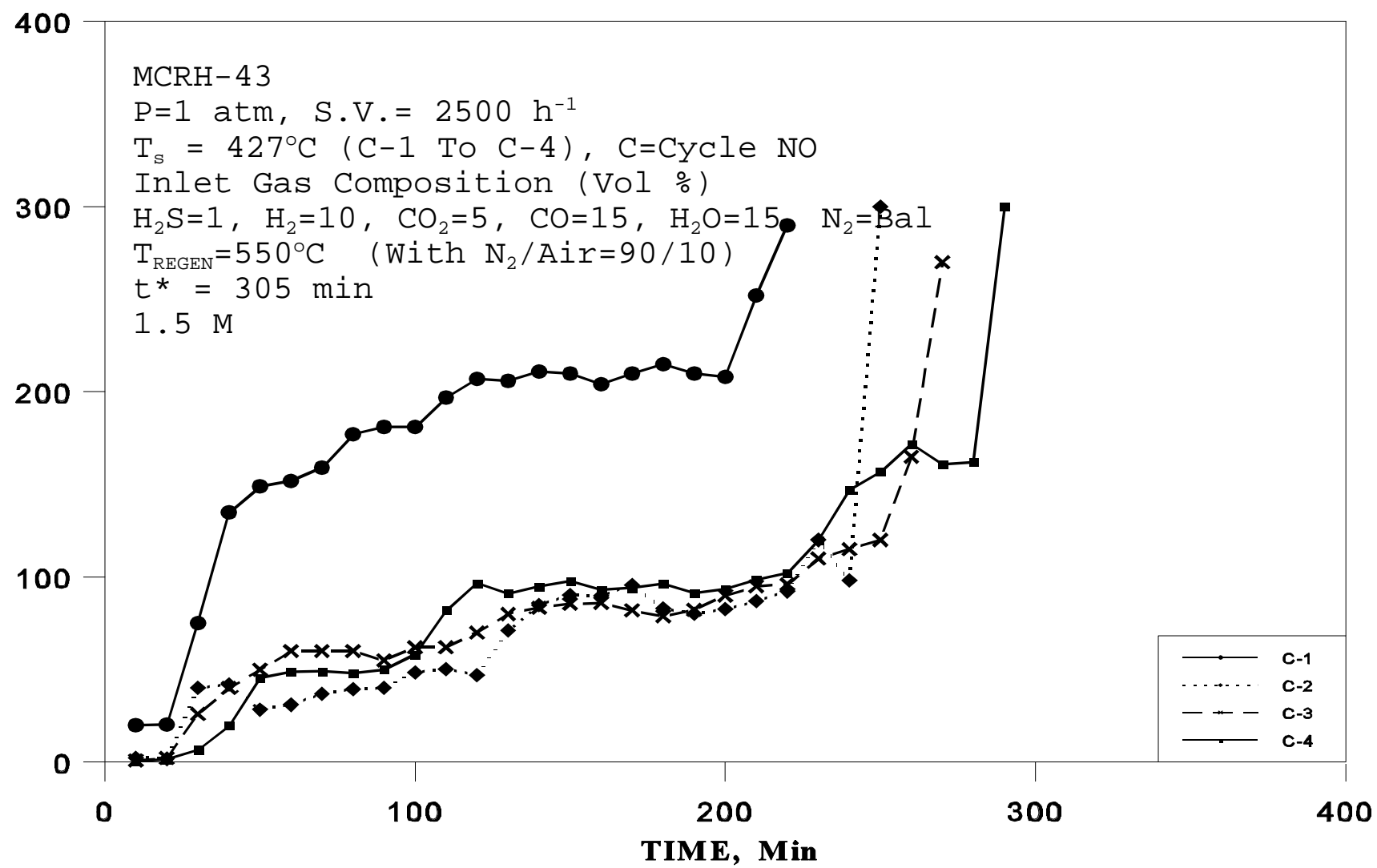

Figure 9. $\mathrm{H}_{2} \mathrm{~S}$ Breakthrough Curves in Successive Sulfidation Cycles of Sorbent MCRH-43 


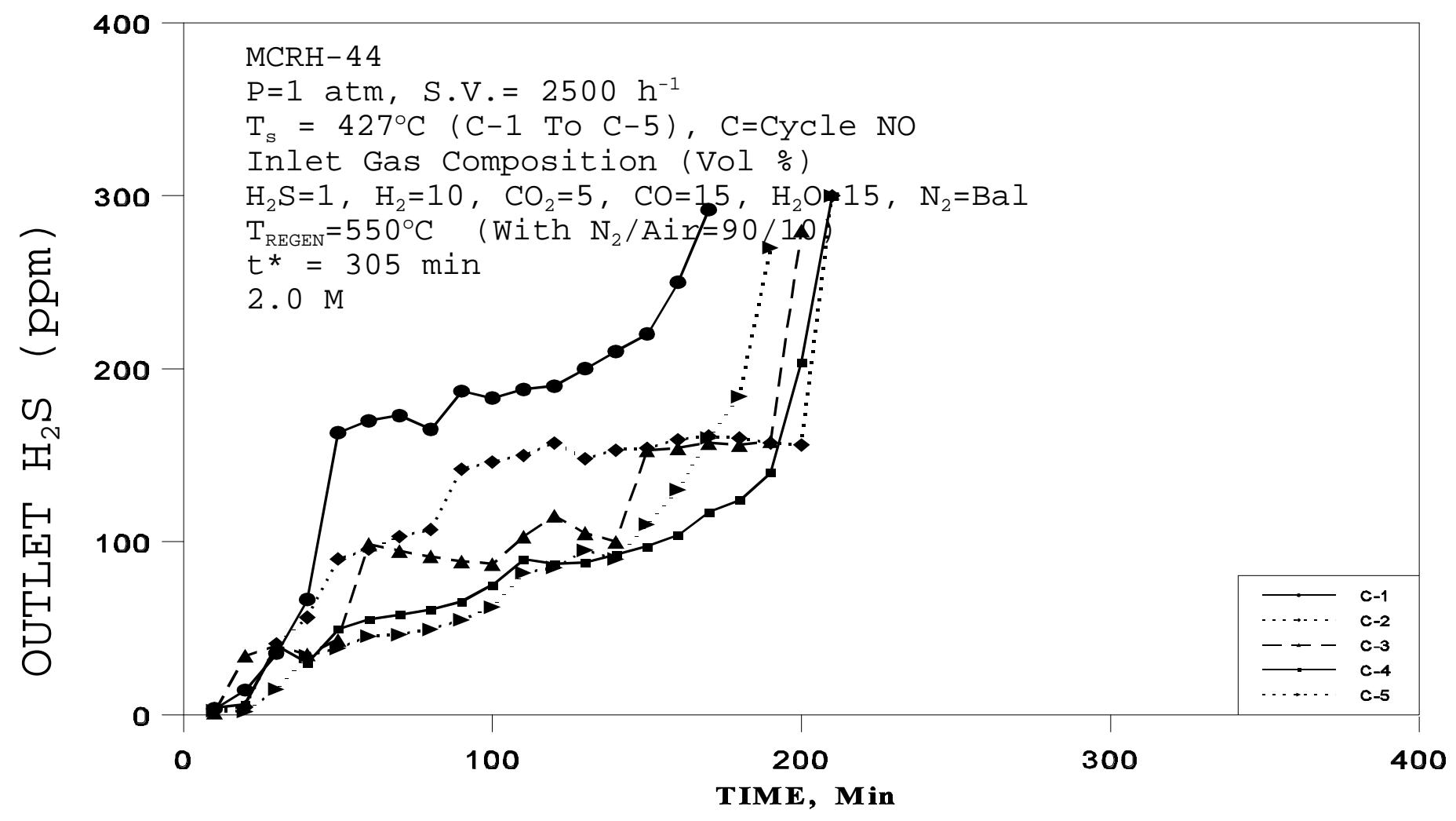

Figure 10. $\mathrm{H}_{2} \mathrm{~S}$ Breakthrough Curves in Successive Sulfidation Cycles of Sorbent MCRH-44 


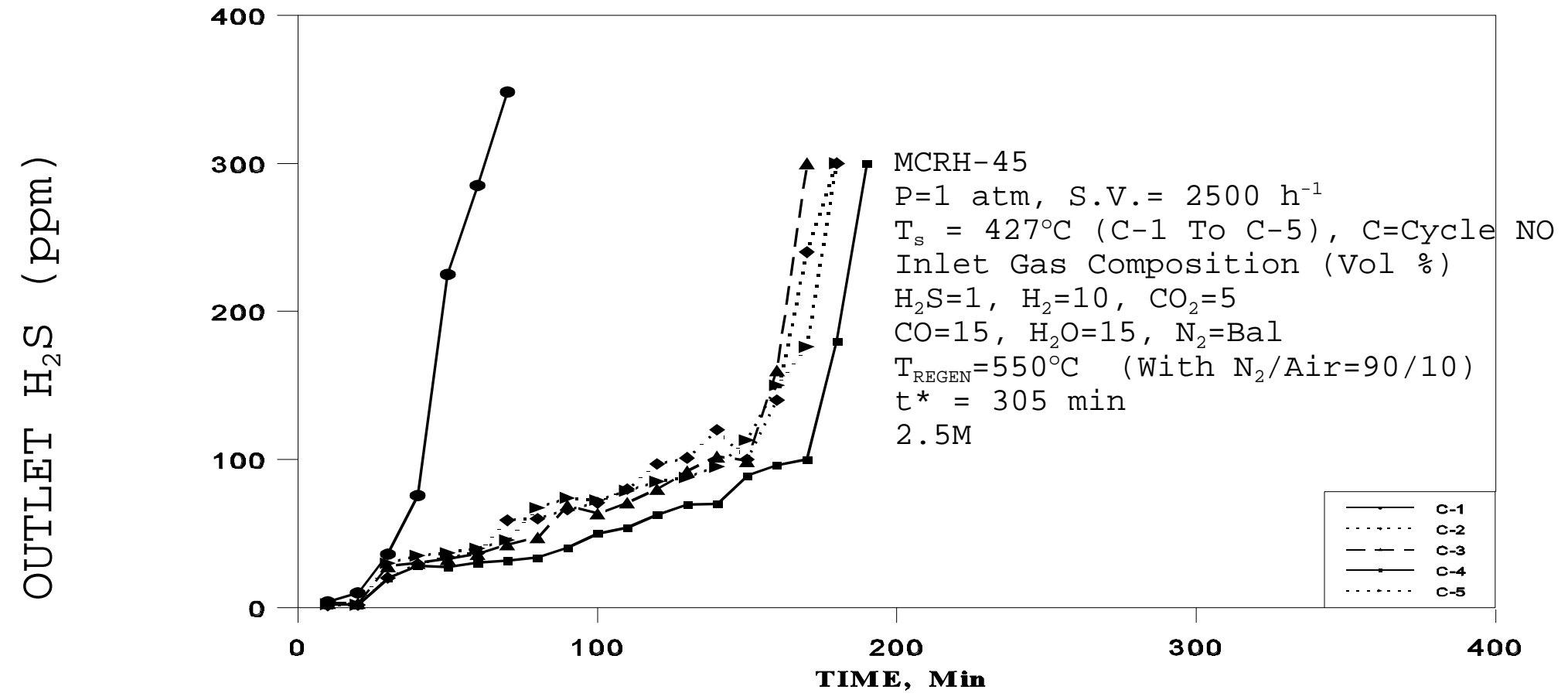

Fig

ure 11. $\mathrm{H}_{2} \mathrm{~S}$ Breakthrough Curves in Successive Sulfidation Cycles of Sorbent MCRH-45 
and the breakthrough conversion was greater than $80 \%$. Regeneration of this sorbent was conducted with 2 volume percent $\mathrm{O}_{2}$ in $\mathrm{N}_{2}$ at $550^{\circ} \mathrm{C}$

\section{Effect of Aging}

In this investigation, the aging time was varied in the practical range from 0-180 min. As shown in Table 1, as the ageing time was increased from 30-90 min (at fixed

molar concentration) almost there is no variation in the physical properties of the sorbent. The SEM morphology of the fresh MCRH 46, 47 and 48 are shown in Figures 12-14.

The ZnO-based sorbents MCRH-46, 47, 48 and 50 were evaluated in a sulfidation gas mixture containing (in vol\%): $\mathrm{H}_{2}=10 \%, \mathrm{CO}=15 \%, \mathrm{CO}_{2}=5 \%, \mathrm{H}_{2} \mathrm{~S}=1.0 \%, \mathrm{H}_{2} \mathrm{O}=15 \%$ and bal $\mathrm{N}_{2}$. Figures 15-18 show the $\mathrm{H}_{2} \mathrm{~S}$ breakthrough profiles as a function of time. The prebreakthrough $\mathrm{H}_{2} \mathrm{~S}$ level was less than 100 ppm and the breakthrough conversion was about $70 \%$. Regeneration of this sorbent was conducted with 2 volume percent $\mathrm{O}_{2}$ in $\mathrm{N}_{2}$ at $550^{\circ} \mathrm{C}$. Based on the above results, of the sorbents tested, M CRH-42 showed excellent sulfidation behavior, which was prepared using $1 \mathrm{M}$ solutions and zero ageing time.

\section{Task 2. Investigation of Scale-Up}


Forming operations to making particles for both fluidized-bed and moving bed was investigated by a balance among several factors, including rheological properties of the mixture, and the necessity to achieve satisfactory strength, an open-pore structure, and high activity for hydrogen sulfide removal. Suitable rheological properties was obtained by incorporating certain organic (e.g. methocel) and inorganic binders (e.g. kaolin and bentonite) and micropore formers.

Initially work was concentrated for moving bed applications on the forming operations of 


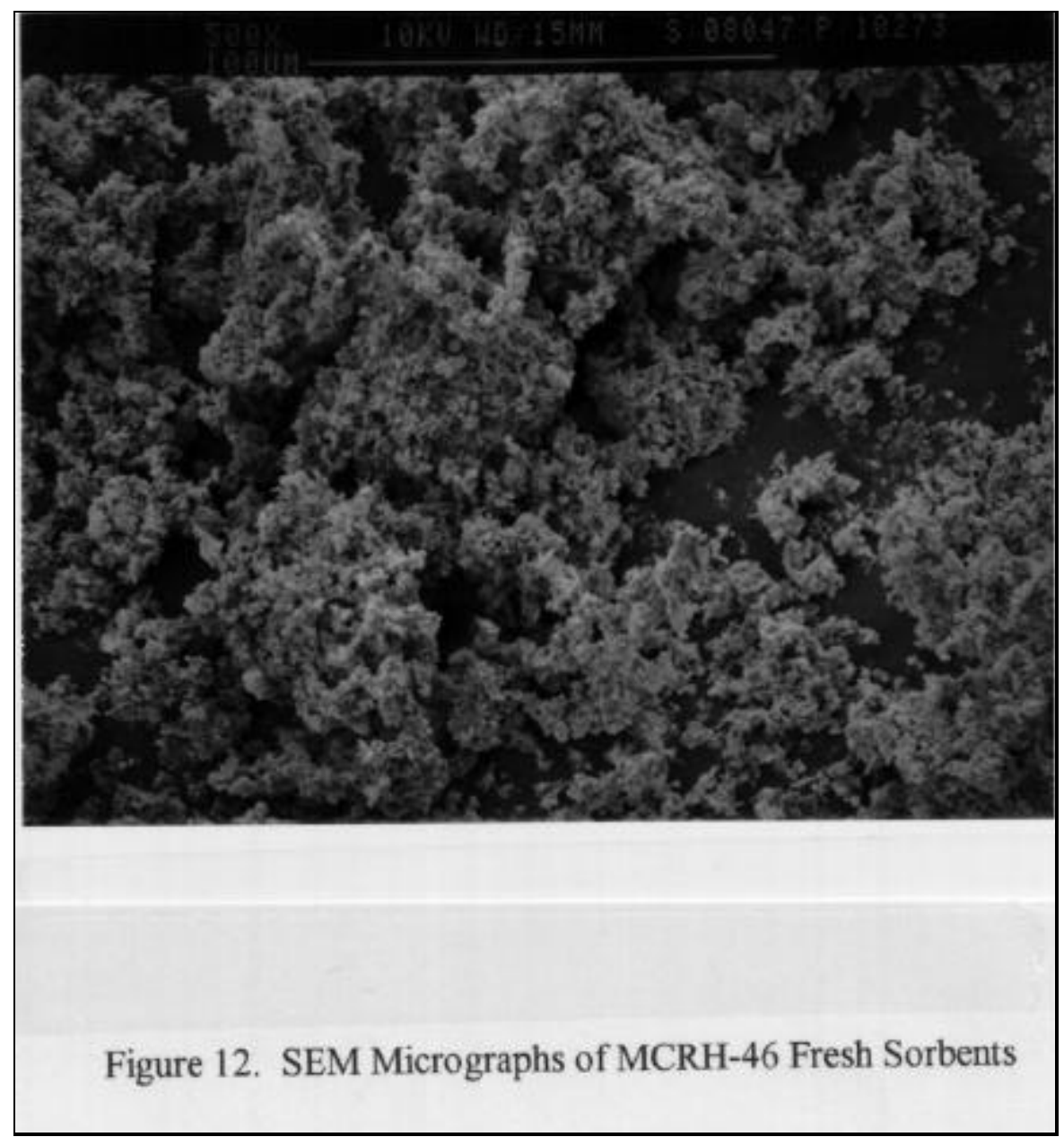




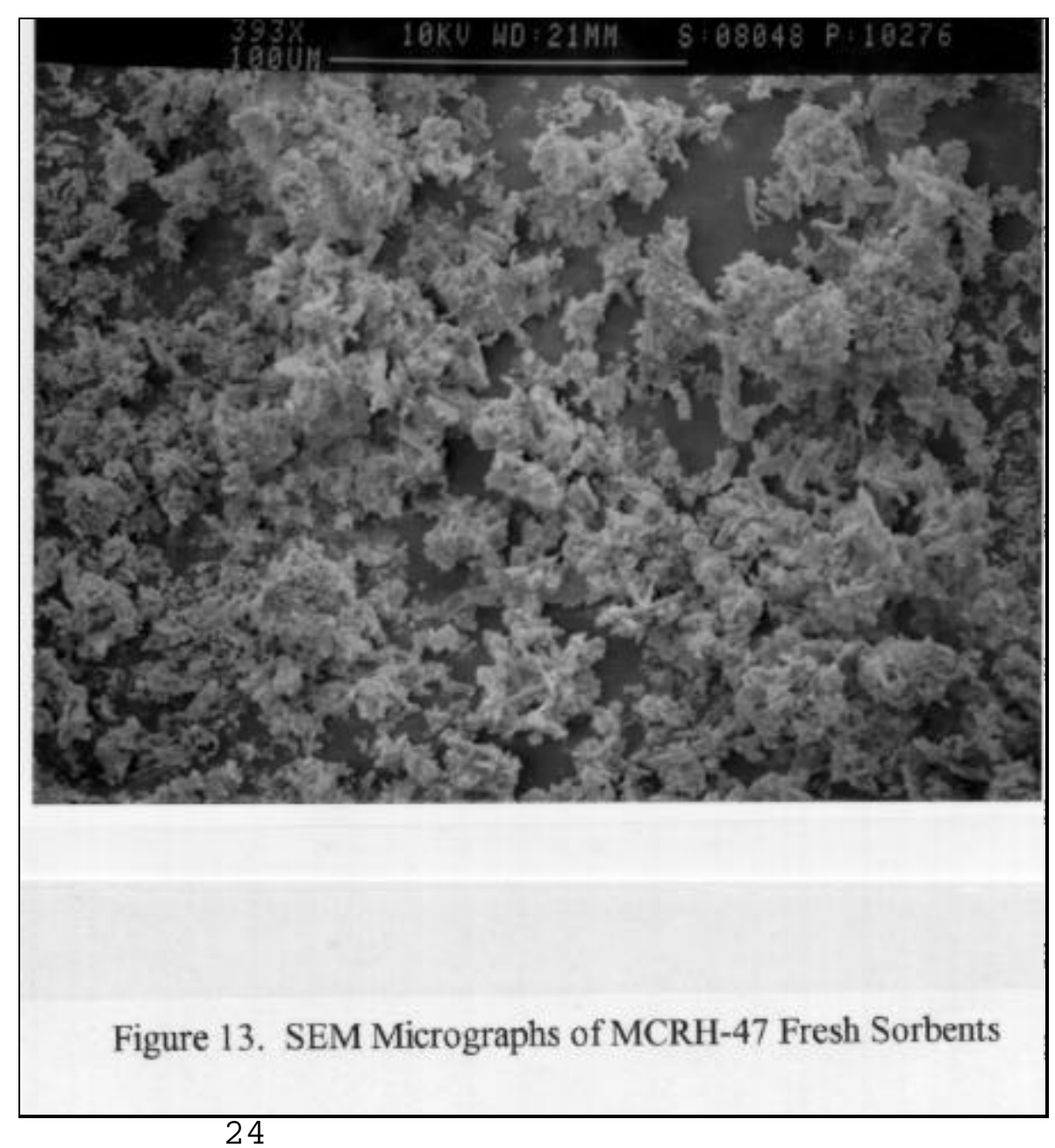




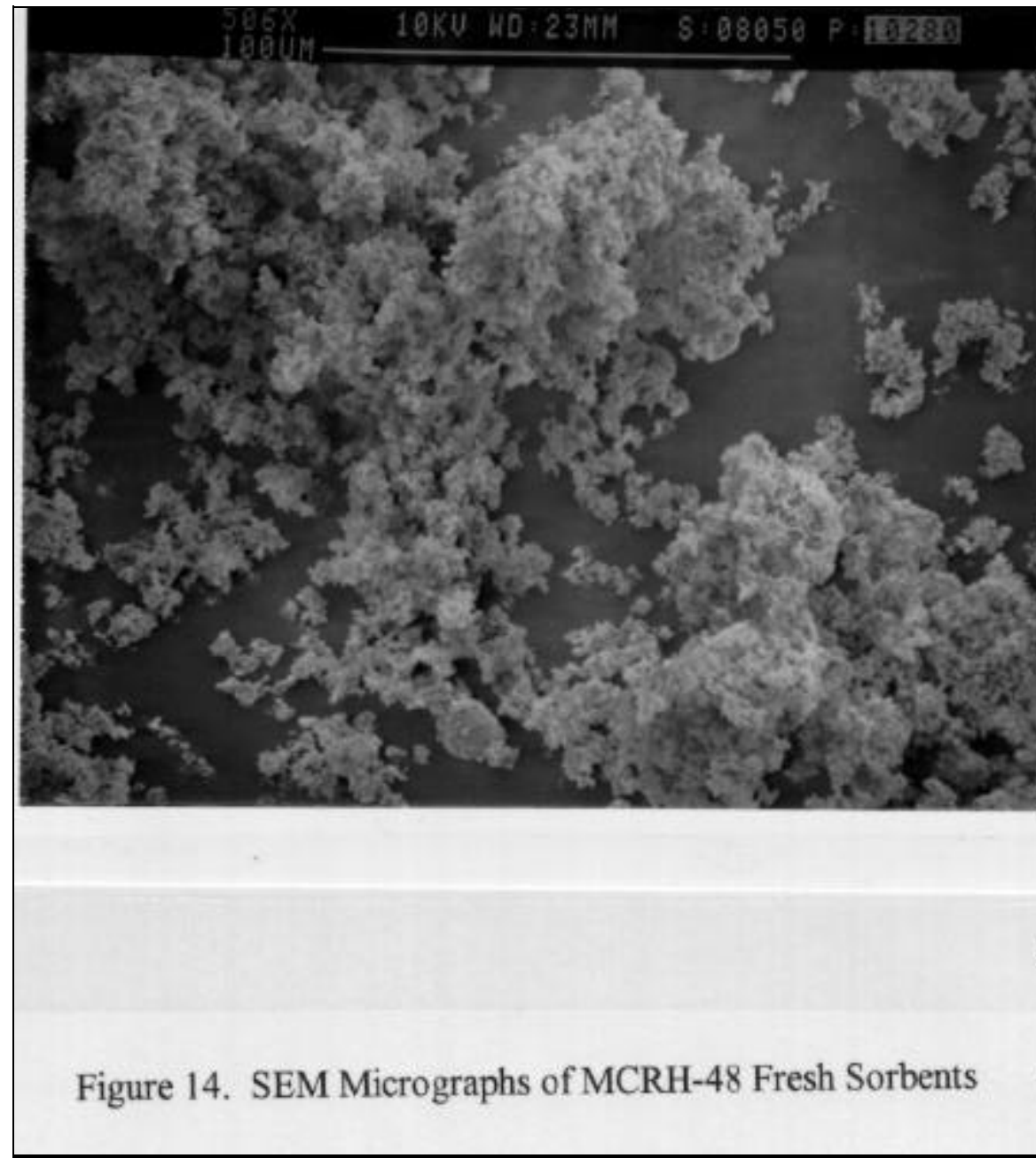




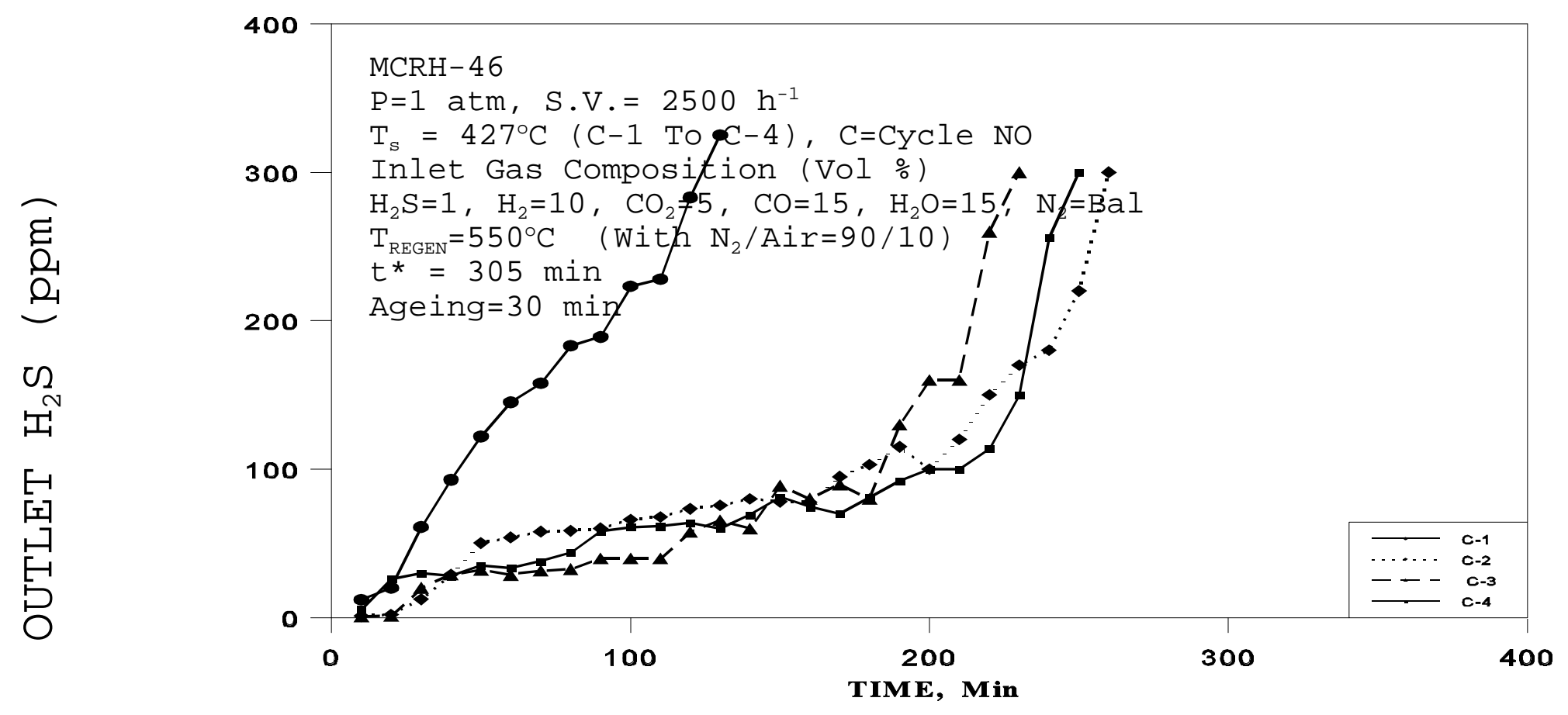

Figure 15. $\mathrm{H}_{2} \mathrm{~S}$ Breakthrough Curves in Successive Sulfidation Cycles of Sorbent MCRH-46 


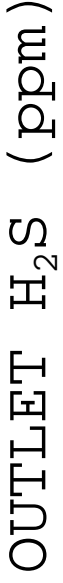

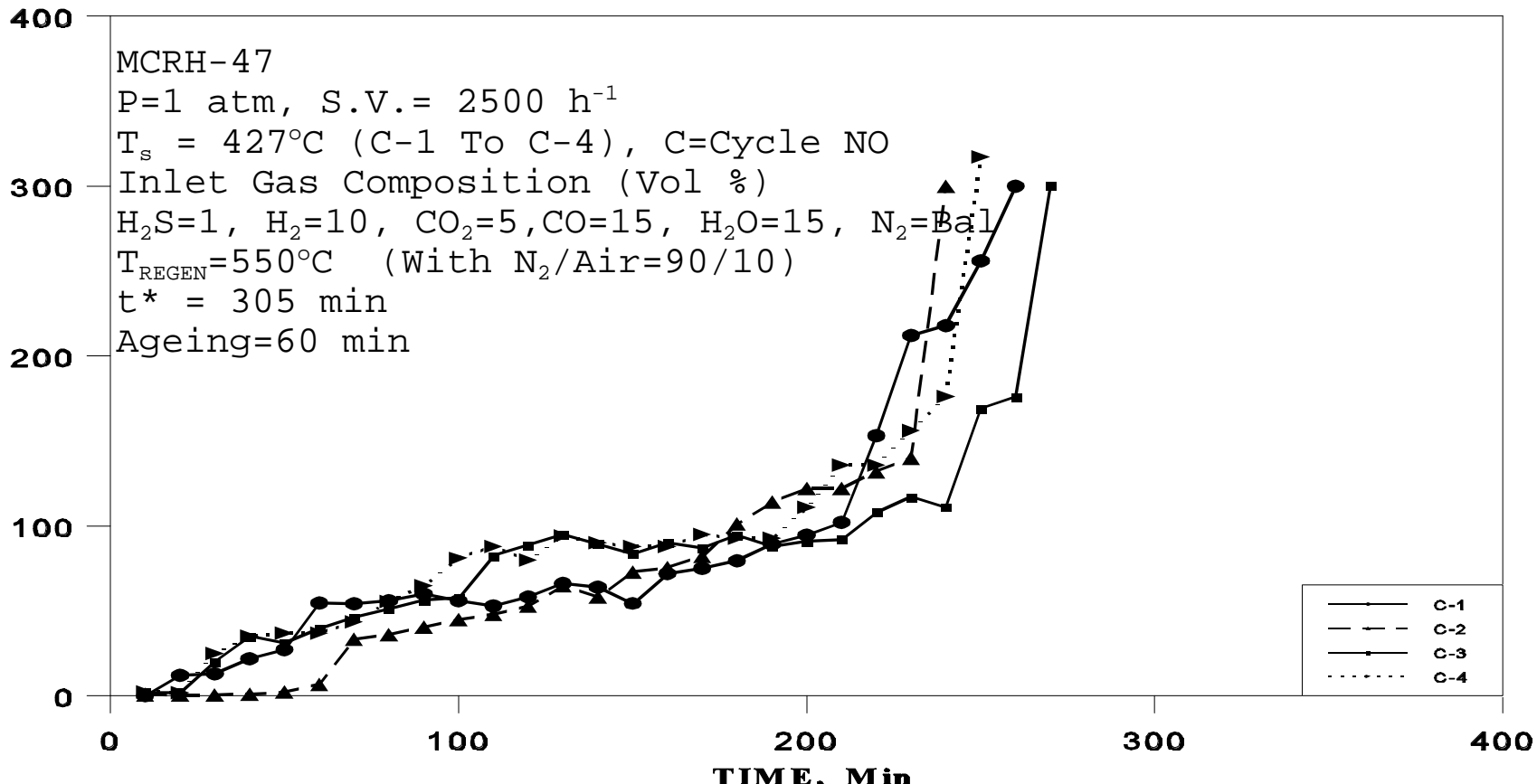

Figure 16. $\mathrm{H}_{2} \mathrm{~S}$ Breakthrough Curves in Successive Sulfidation Cycles of Sorbent MCRH-47 


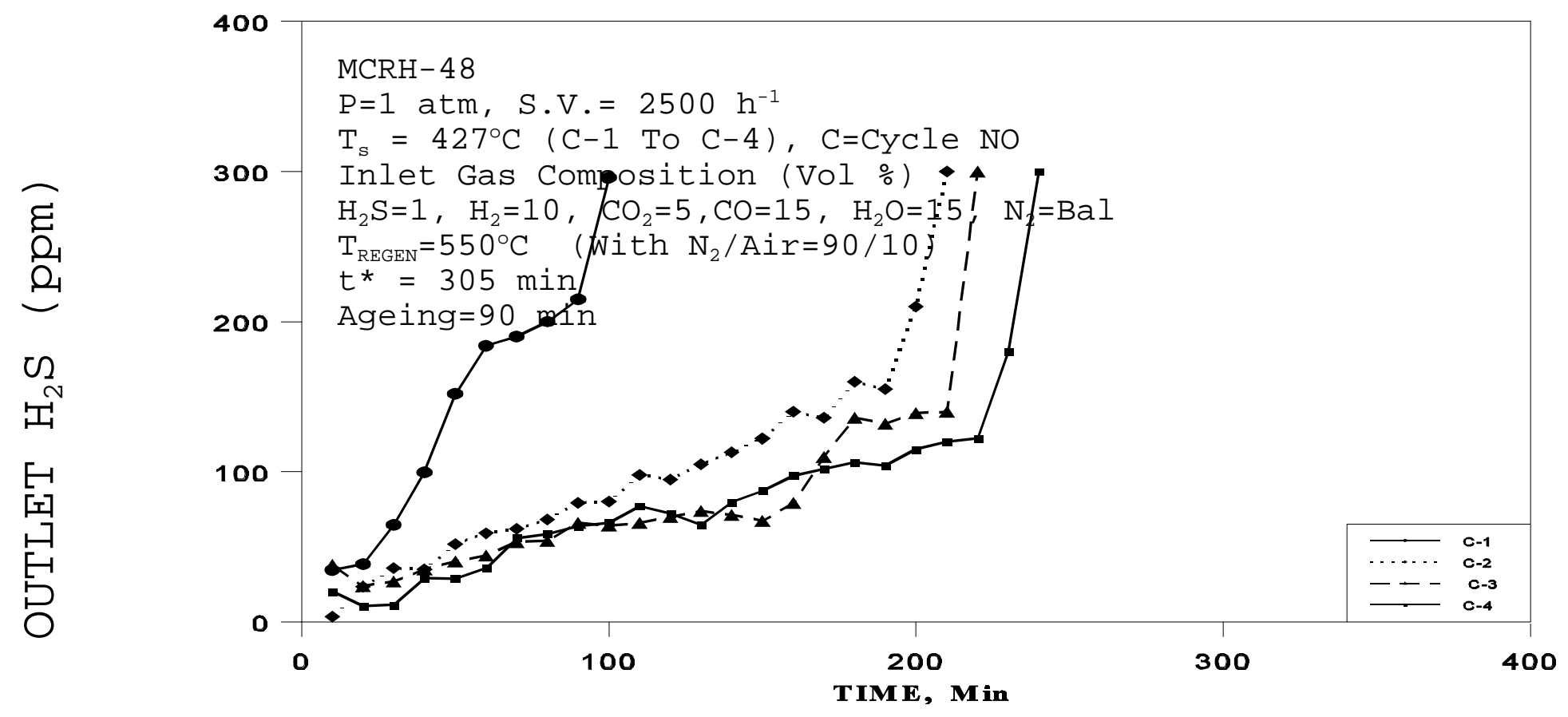

Figure 17. $\mathrm{H}_{2} \mathrm{~S}$ Breakthrough Curves in Successive Sulfidation Cycles of Sorbent MCRH-48 


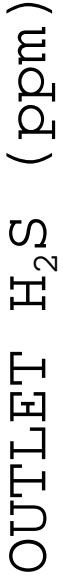

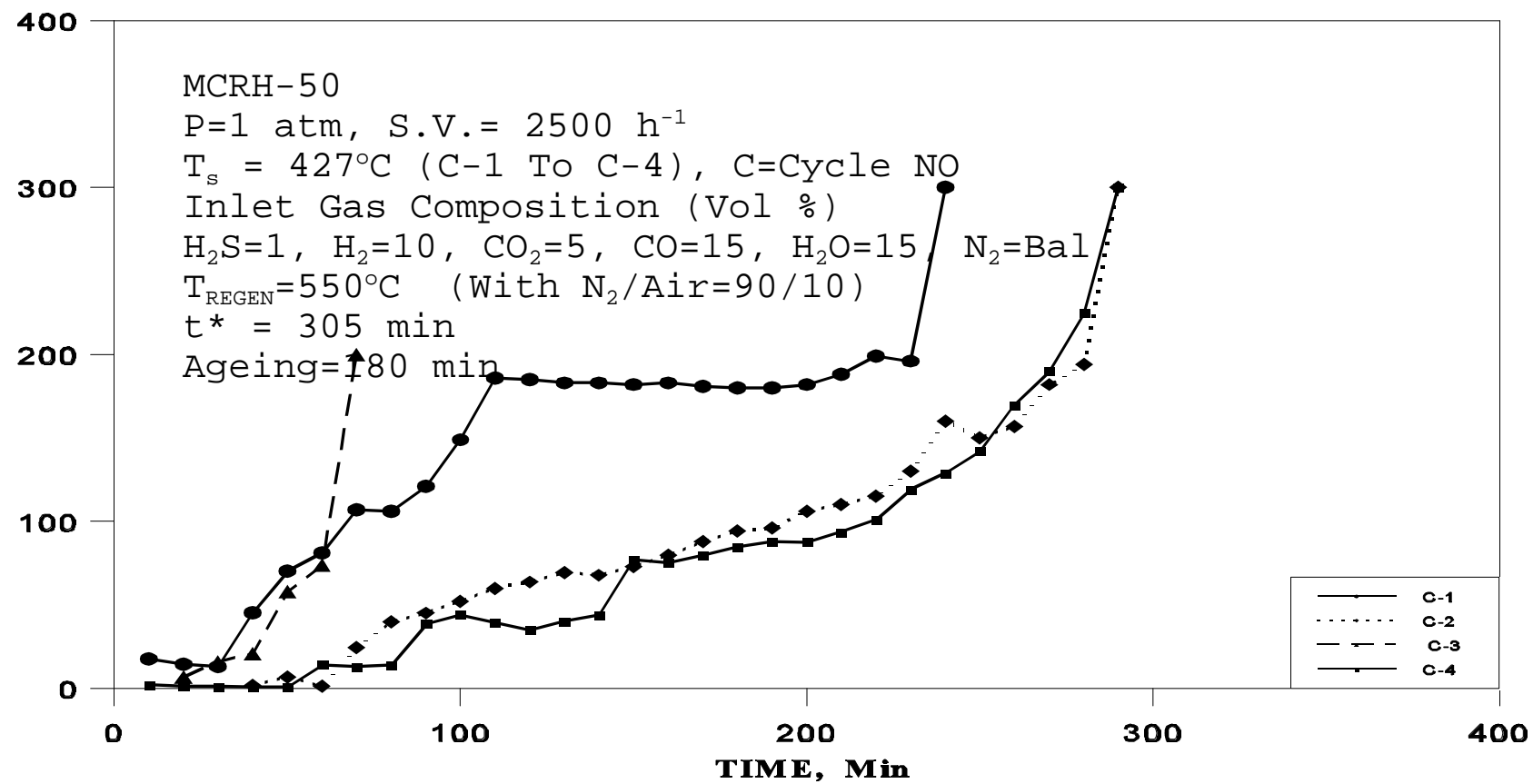

Figure 18. $\mathrm{H}_{2} \mathrm{~S}$ Breakthrough Curves in Successive Sulfidation Cycles of Sorbent MCRH-50 
superior zinc-based sorbent (designated by MCRH-25) material to improve the strength of the material. Following list provides the work done to improve the strength of the pellet by UCI. PP-3488 $3000 \mathrm{~g}$ oxides dried at $302^{\circ} \mathrm{F}$ overnight, $2.5 \%$ bentonite, $5 \%$ kaolin, pelletize $.11-$ .12

PP-3488-1 $3000 \mathrm{~g}$ oxides dried at $302^{\circ} \mathrm{F}$ overnight, $2.5 \%$ bentonite, $5 \%$ kaolin, $3 \%$ starch, pelletize $.11-.12$

PP-3512 $2500 \mathrm{~g}$ oxides calcined at $537^{\circ} \mathrm{C}$ for 1 hour, $2.5 \%$ bentonite, $5 \%$ kaolin, pelletize .12

$\underline{\text { PP-3563-1 }} 3000 \mathrm{~g}$ oxides calcined at $537^{\circ} \mathrm{C}$ for 1 hour, $5 \%$ bentonite, pelletize $.11-.12$

PP-3563-2 $3000 \mathrm{~g}$ oxides calcined at $537^{\circ} \mathrm{C}$ for 1 hour, $5 \%$ bentonite, 0.25 methocel, pelletize $.11-.12$

PP-3588 $3000 \mathrm{~g}$ oxides $\left(5 \%\right.$ bentonite in ppt) calcined at $315^{\circ} \mathrm{C}$ overnight, $5 \%$ bentonite PP-3589 $3000 \mathrm{~g}$ ball-milled oxides (5\% bentonite in ppt) calcined at $315^{\circ} \mathrm{C}$ overnight, $5 \%$ bentonite

All of the samples had $<5 \mathrm{lb}$ crush strength when calcined at $700-750^{\circ} \mathrm{C}$.

\section{Attrition-Resistant Sorbents}

This section describes the efforts directed towards the development of sorbents for fluidized-bed reactors. Our $50 \mathrm{~g}$ batch sorbent preparation set up was scaled up to $500 \mathrm{~g}$ sorbent material. The preparation technique and the formulations are proprietary, pending a patent application. Thus no details regarding the technique are divulged in this report. United Catalysts, Inc (UCI) provided the required input to keep the preparation procedure on a commercial track 
by making sure that the techniques were scalable.

The Sierra-Pacific plant employs the M.W.Kellogg (Kellogg) circulating fluidized-bed (transport) HGD process whereas the TECO plant employs the General Electric (GE) movingbed HGD process. The key barrier issues facing the successful development of a fluidized-bed HGD process are chemical degradation, physical attrition, high regeneration light-off (initiation) temperature compared to sulfidation temperature, and high cost of the sorbent. Current leading first generation sorbents such as zinc titanate (ZT-4) typically prepared with an average particle size (aps) of $170 \mu \mathrm{m}$ using a granulator and Phillips Petroleum's Z-Sorb III (175 $\mu \mathrm{m}$ aps) undergo significant chemical degradation, losing their reactivity and capacity by as much as 50 $\%$ in just 50 cycles and they cost as much as $\$ 8-10$ per $1 \mathrm{lb}$. These sorbents also have very low attrition resistance compared to bench-mark fluid catalytic cracking (FCC) catalysts (70-80 $\mu \mathrm{m}$ aps) prepared by spray drying and employed in a petroleum refinery. The larger aps of $170 \mu \mathrm{m}$ results in reduced entrainment and allows greater throughput and flexibility in the choice of reactor type, but has not to date been successfully made using a spray drier. Also the regeneration light-off temperature of first generation zinc titanate sorbents is around $630-650^{\circ} \mathrm{C}$, which is unacceptably higher than the $480-550^{\circ} \mathrm{C}$ sulfidation temperature being employed at Sierra. To allow efficient heat integration, the sulfidation and regeneration light-off temperatures need to be the same or quite close to each other.

Fluidized-bed HGD systems are also receiving a lot of emphasis due to several potential advantages over fixed- and moving-bed reactors, including excellent gas solid contact, fast kinetics, pneumatic transport, ability to handle particles in the gas, and ability to control the 
highly exothermic regeneration process. However, an attrition-resistant sorbent that can withstand stresses induced by fluidization, transport, chemical transformation, and rapid temperature swings must be developed.

A series of MCRH sorbents was prepared in attrition resistant form with up to $75 \%$ binder to provide a hard material. This results in a loss of capacity but for Sierra, a capacity of only $5 \mathrm{~g} / 100 \mathrm{~g}$ is sufficient. The reactivity and regenerability are the more important parameters. Table 2 shows that the attrition resistance of the MCRH sorbents prepared with our proprietary binder is extremely high compared to first generation sorbents and it satisfies the target of Table 3, set by Kellogg.

Table 2. Attrition Test of MCRH Sorbents

\begin{tabular}{|l|l|l|}
\hline \multirow{2}{*}{ Sorbent } & \multicolumn{2}{|l|}{ 3-hole attrition loss (wt \%) } \\
\cline { 2 - 3 } & 5 hour & 20 hour \\
\hline MCRH-51 & 0.00 & 0.62 \\
\hline MCRH-53 & 0.28 & 0.56 \\
\hline MCRH-54 & 0.36 & 0.36 \\
\hline MCRH-55 & 0.56 & 1.41 \\
\hline MCRH-56 & 0.00 & 1.06 \\
\hline MCRH-61 & 1.2 & 0.7 \\
\hline ZT-4 & 40.00 & 89.00 \\
\hline
\end{tabular}

The sorbent selection criteria for the Sierra plant provided by Kellogg are shown in Table 3.

Table 3: Sorbent Selection Criteria for Sierra-Pacific

Sulfidation

1 to $2 \mathrm{~s}$ contact time

$<10$ ppmv $\mathrm{H}_{2} \mathrm{~S}$ leakage

482 to $538^{\circ} \mathrm{C}$ operation

Regeneration

\section{Properties}

$80 \mu \mathrm{m}$ aps

$>50 \mathrm{lb} / \mathrm{ft}^{3}$ bulk density

\section{Attrition}


$<538^{\circ} \mathrm{C}$ light-off

no $\mathrm{O}_{2}$ breakthrough

neat air oxidation
$<2.5 \times 10^{-5} \mathrm{lb} / \mathrm{lb}$ circulated (TRTU)

3-hole air-jet attrition $<5 \%$

in 5 hours

MCRH-61: A fluidzable zinc oxide-based sorbent was prepared, using the proprietary

technique. The sorbent was dried at $120^{\circ} \mathrm{C}$ and then calcined in an oxygen-containing atmosphere at $600^{\circ} \mathrm{C}$ for 2 hours.

Figure 19 shows the breakthrough profiles for the zinc-based sorbent MCRH-61. It was tested for 50 cycles of sulfidation in the laboratory-scale reactor at $482^{\circ} \mathrm{C}$. Regeneration between cycles was conducted with 2 volume percent $\mathrm{O}_{2}$ in $\mathrm{N}_{2}$ at $550^{\circ} \mathrm{C}$. The gas hourly space velocity for the 50-cycle test was about $2500 \mathrm{~h}^{-1}$ both in sulfidation and in regeneration. Sulfidation tests were carried out with a sulfidation gas containing (vol\%): $\mathrm{H}_{2}=10 \%, \mathrm{CO}=15 \%, \mathrm{CO}_{2}=5 \%$, $\mathrm{H}_{2} \mathrm{~S}=0.4 \%, \mathrm{H}_{2} \mathrm{O}=15 \%$ and bal $\mathrm{N}_{2} . \mathrm{MCRH}-61$ sorbent showed excellent sulfidation behavior. The pre-breakthrough $\mathrm{H}_{2} \mathrm{~S}$ level was less than $100 \mathrm{ppm}$ and the breakthrough conversion was 100\%. There was no deactivation in even after $\mathbf{5 0}$ cycles in this fixed bed study.

Based on fixed-bed microreactor screening, MCRH-61 was found to be best attritionresistant fluidizable sorbent and was selected for high temperature, high pressure (HTHP) testing. It was tested in the 2.0 inch HTHP fluidized-bed reactor (Figure 20) at RTI simulating the SierraPacific conditions for 10 cycles at sulfidation conditions of simulated Kellogg gasifier gas with $0.4 \% \mathrm{H}_{2} \mathrm{~S}$ at $18.8 \mathrm{~atm}$ pressure, $480-510^{\circ} \mathrm{C}$, and $15 \mathrm{slpm}$ through a $145 \mathrm{~g}$ sorbent bed. The regeneration was conducted with pure air with an initial temperature of $480-510^{\circ} \mathrm{C}$. The $\mathrm{H}_{2} \mathrm{~S}$ breakthrough results shown in Figure 21 indicate essentially complete removal of $\mathrm{H}_{2} \mathrm{~S}$ until a sharp breakthrough in all 10 cycles. The sorbent lost some capacity after the first cycle presumably due to pure air regeneration that increased the bed temperature to around $700^{\circ} \mathrm{C}$. 


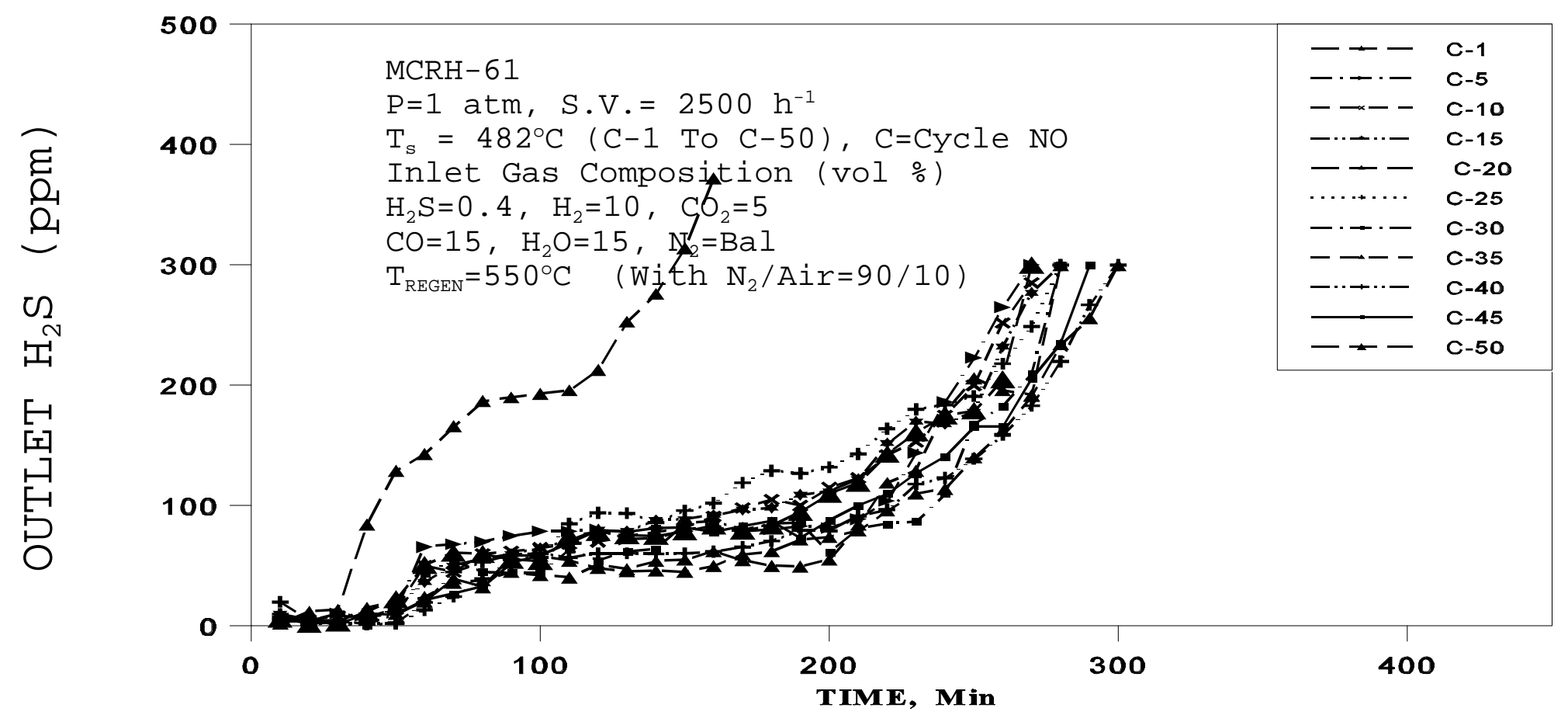

Figure 19. $\mathrm{H}_{2} \mathrm{~S}$ Breakthrough Curves in Successive Sulfidation Cycles of MCRH-61 Sorbent 


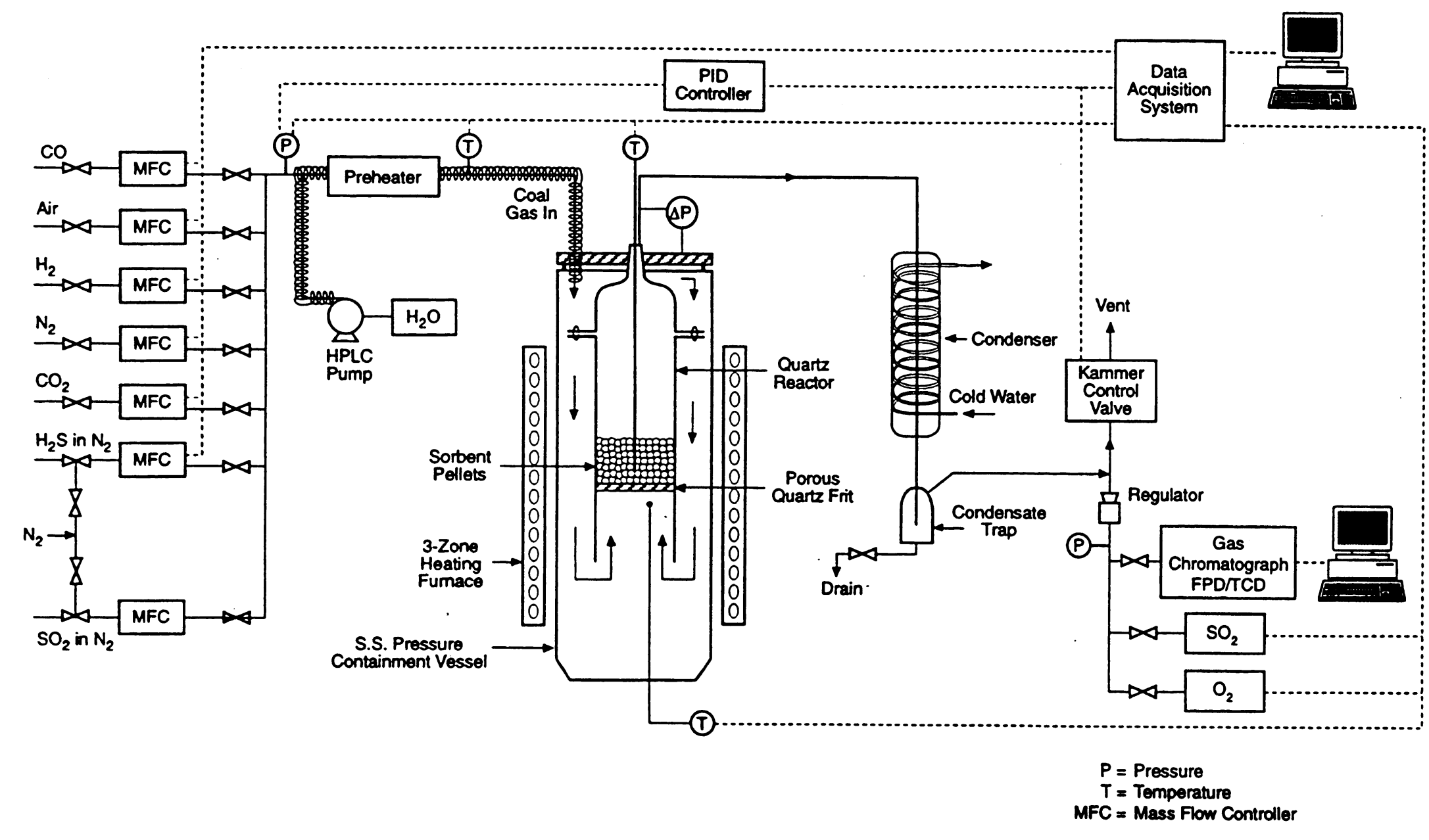

Figure 20 RTI Bench-Scale Test Facility 


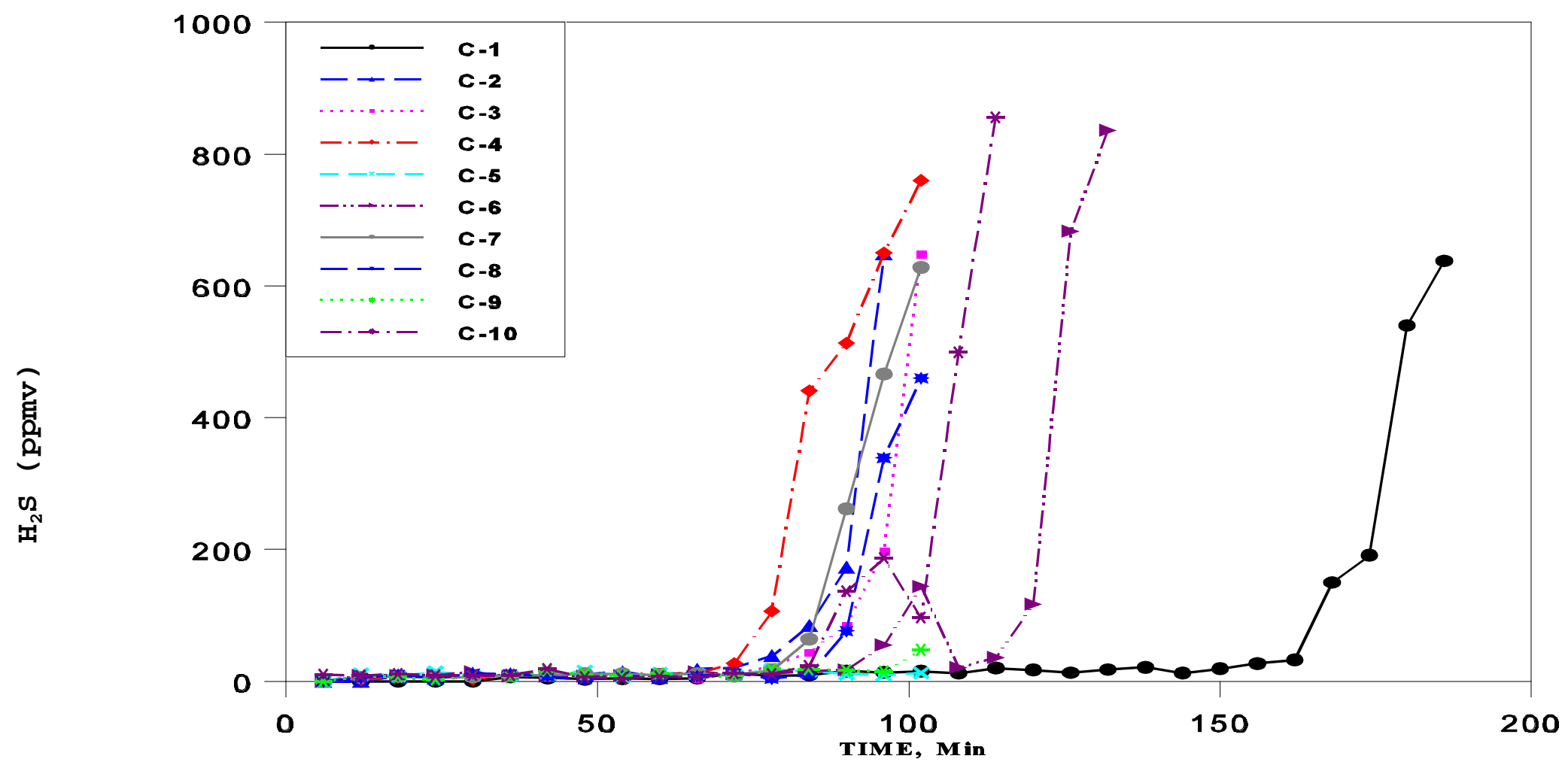

Figure 21. Breakthrough Behavior of MCRH-61 
After the first cycle, the capacity stabilized even with temperature excursions to $675-700^{\circ} \mathrm{C}$ and no attrition of the sorbent occurred in the 10 cycle test. Due to pure air regeneration, some sulfate formation did occur as seen from the $\mathrm{SO}_{2}$ evolution curves for cycles 2-10 during sulfidation (Figure 22). The sulfur loading is shown in Figure 23. The sorbent lighted-off nicely at $482^{\circ} \mathrm{C}$. Figure 24 shows the $\mathrm{SO} 2$ elution profile versus regeneration time. Overall the test is a success with potential for an optimized MCRH-61 to be a candidate for Sierra-Pacific. The cause of the reactivity drop during the first cycle and stabilization thereafter needs to be evaluated.

\section{TASK 3: PREPARATION OF 100 LB BATCH}

UCI prepared a $100 \mathrm{lb}$ batch of a modified MCRH-61 (MCRH-67) sorbent to demonstrate commercial readiness. The properties of the sorbent is given below:

\begin{tabular}{|l|l|l|l|}
\hline \multirow{2}{*}{ Designation } & BET & \multicolumn{2}{|l|}{ 3-hole attrition loss (wt \%) } \\
\cline { 3 - 4 } & $\begin{array}{l}\text { Surface } \\
\text { Area } \\
\mathrm{m}^{2} / \mathrm{g}\end{array}$ & 5 hour & hour \\
\hline MCRH-67(Prepared at Hampton) & 101.1 & 1.2 & 0.7 \\
\hline MCRH-67(Prepared at UCI)100 lb Batch & 70.2 & 1.2 & 0.7 \\
\hline
\end{tabular}

As seen in the above table, attrition properties of the both sorbents are the same. 


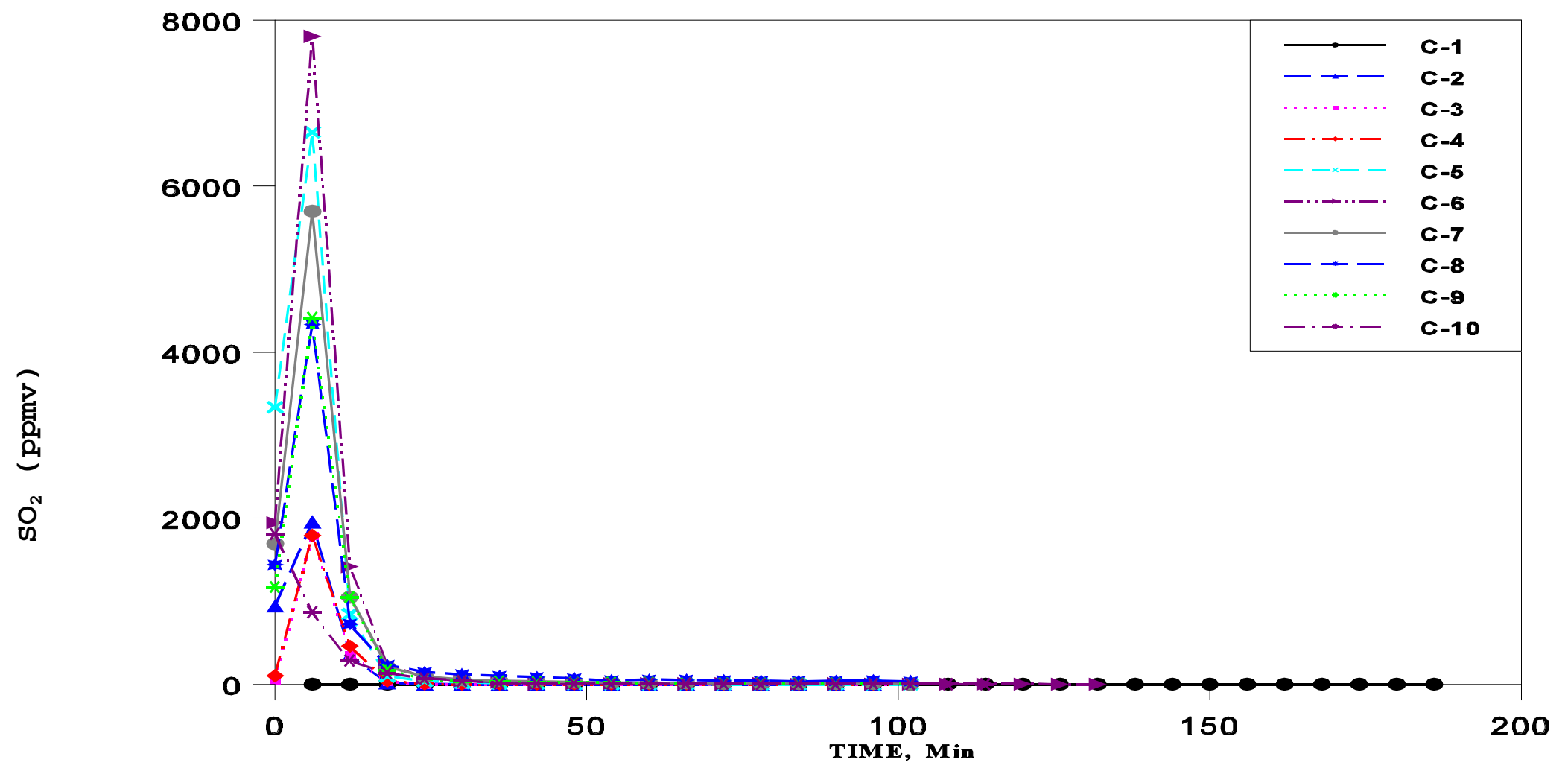

Figure 22. $\mathrm{SO}_{2}$ Evolution During Sulfidation Due to sulfation 


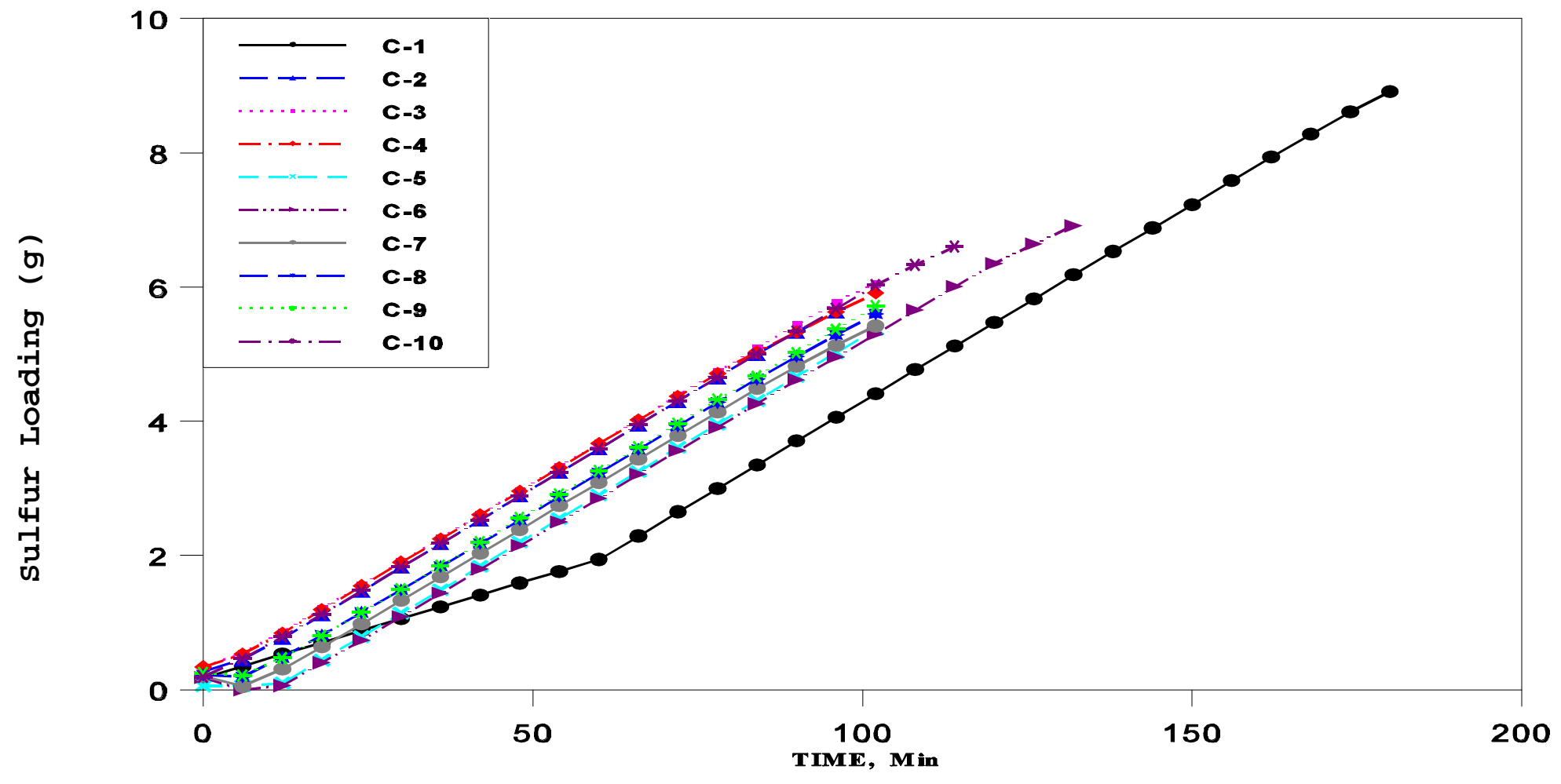

Figure 23. Cumulative Sulfur Loading for MCRH-61 


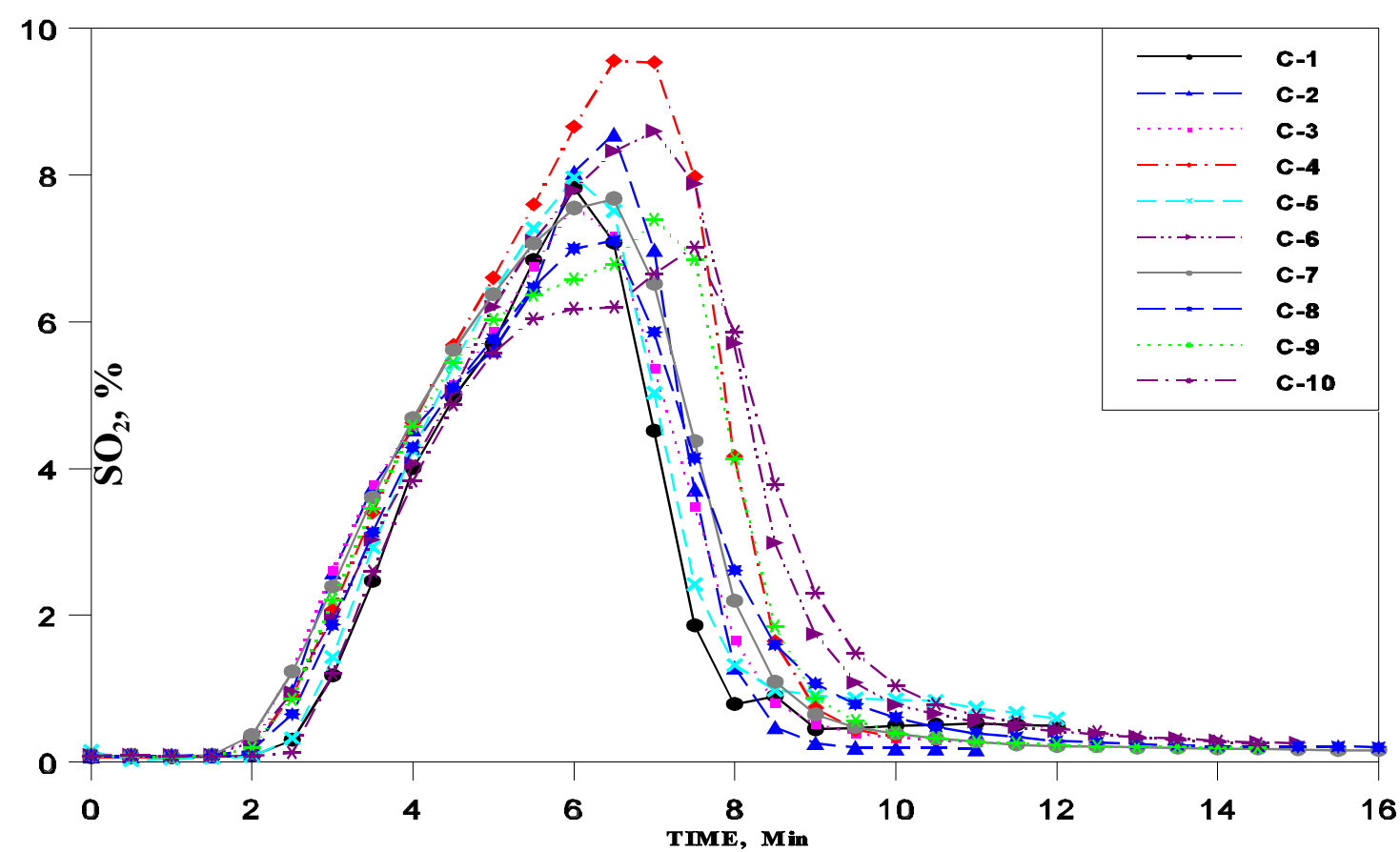

Figure 4. Regeneration of MCRH-61 


\subsection{CONCLUSIONS}

The techniques employed in this project have successfully demonstrated the feasibility of preparing sorbents that achieve greater than $99 \% \mathrm{H}_{2} \mathrm{~S}$ removal at temperature of $427^{\circ} \mathrm{C}$ and that retain their activity over 50 cycles. Fundamental understanding of phenomena leading to chemical deactivation and high regeneration light-off temperature has enabled us to successfully prepare and scale up a MCRH-61 sorbent that showed no loss in reactivity and capacity over 50 cycles.

This sorbent removed $\mathrm{H}_{2} \mathrm{~S}$ to below 20 ppmv and lighted-off nicely at $480^{\circ} \mathrm{C}$ during regeneration.

Overall the test is a success with potential for an optimized MCRH-61 to be a candidate for Sierra-Pacific. Further required modifications to improve its performance is being addressed in a follow up grant (DE-FG26-97FT97276) to Hampton University by DOE 


\subsection{RECOMMENDATIONS}

Future work should address the following issues:

-Because the complex nature of coal gas cannot be duplicated completely in the laboratory, additional parametric and long term tests on an optimized MCRH-61 sorbent should be performed at high pressure and practical IGCC temperatures as low as $343^{\circ} \mathrm{C}$.

- Further studies should be aimed toward determining the effect of trace contaminants such as chloride, alkali, and particulates on the sorbent kinetics and performance

-Testing of improved MCRH-61 sorbents should be carried out in bench-scale fluidized-bed reactors and M.W. Kellogg's transport reactor test unit. 


\subsection{REFERENCES}

Flytzani-Stephanopoulos, M., and Jothimurugesan, K., "Preparation of Extrusions of Bulk Mixed Oxide Compounds with High Macroporosity and Mechanical Strength, U. S. Patent, 4,977,123, 1990.

Gangwal, S.K., et al. 1988. "Bench-Scale Testing of Novel High-Temperature Desulfurization Sorbents.” Report No. DOE/MC/23126-2662 (DE89000935).

Gangwal, S.K., R. Gupta, and W.J. McMichael. 1995. "Hot-Gas Cleanup-Sulfur RecoveryTechnical, Environmental, and Economic Issues," Heat Recovery Systems and CHP. Vol. 15, No. 2, p. 205-214, Elsevier Science Limited.

Jothimurugesan, K. and Harrison, D. P., "reaction Between $\mathrm{H}_{2} \mathrm{~S}$ and Zinc Oxide -Titanium Oxide Sorbents. 2. Single-Pellet Sulfidation Modeling."Ind.Eng.Chem.Res, 29, 1167(1990).

NOVEM. 1991. "System Study High Temperature Gas Cleaning at IGCC Systems.” Netherlands Agency for Energy and the Environment.

Woods, M. C., Gangwal., S. K. Harrison, D. P. and Jothimurugesan, K.,"Kinetics of the Reactions of a Zinc Ferrite Sorbent in High-Temperature Coal Gas Desulfurization" Ind.Eng.Chem.Res., 30, 100(1991).

Woods, M. C. Gangwal, S. K., Jothimurugesan, K. and Harrison, D. P. "Reaction Between $\mathrm{H}_{2} \mathrm{~S}$ and Zinc Oxide-Titanium Oxide sorbents. 1. Single-Pellet Kinetic Studies" Ind.Eng.Chem.Res 29, 1160(1990) 